\title{
Anabases
}

ANABASES Traditions et réceptions de l'Antiquité

$24 \mid 2016$

Varia

\section{Les statues des bains de Zeuxippe à Constantinople: collection et patrimoine dans l'Antiquité tardive}

Vincent Puech

\section{CpenEdition}

\section{Journals}

Édition électronique

URL : http://journals.openedition.org/anabases/5945

DOI : 10.4000/anabases.5945

ISSN : 2256-9421

Éditeur

E.R.A.S.M.E.

Édition imprimée

Date de publication : 10 novembre 2016

Pagination : 145-181

ISSN : 1774-4296

\section{Référence électronique}

Vincent Puech, « Les statues des bains de Zeuxippe à Constantinople : collection et patrimoine dans

I'Antiquité tardive », Anabases [En ligne], 24 | 2016, mis en ligne le 01 octobre 2019, consulté le 23 mars 2020. URL : http://journals.openedition.org/anabases/5945; DOI : https://doi.org/10.4000/anabases. 5945

(c) Anabases 
Anabases 24 (2016), p. 145-181.

\section{Les statues des bains de Zeuxippe à Constantinople : collection et patrimoine dans l'Antiquité tardive}

Vincent PuEch

“C'est d'après les tableaux du peintre Zeuxis, dont il fit un grand nombre, que certains pensent que le bain de Byzance a été appelé „’ : ainsi s'exprime $\mathrm{au} \mathrm{XvI}^{\mathrm{e}}$ siècle le voyageur et humaniste français Pierre Gilles, le premier grand connaisseur occidental des monuments de Constantinople. Cette association fantaisiste des bains de Constantinople au peintre grec du v siècle av. J.-C. Zeuxis d’Héraclée, fameux pour son réalisme, révèle bien la célébrité et la qualité de leur décor. Ces bains furent construits par Constantin entre l'entrée du palais impérial et celle de l'hippodrome, ce qui montre leur place centrale dans l'urbanisme de la nouvelle capitale. Ils ont brûlé lors de la révolte Nika de 532, ce qui nous a irrémédiablement privés des nombreuses statues de bronze qu'ils renfermaient. Par chance, cette riche collection a été décrite en grec, au tournant des $\mathrm{v}^{\mathrm{e}}$ et $\mathrm{vi}^{\mathrm{e}}$ siècles, par le poète Christodoros de $\operatorname{Coptos}^{2}$. Celui-ci nous livre une description crédible de soixante-dix statues individuelles ou groupes statuaires : ce sont pour

1 Qu'il me soit permis de dédier ces pages à la mémoire de Gilbert Dagron et de Claude Lepelley, disparus en 2015. Pierre Gilles, Itinéraires byzantins, trad. J.-P. Grélois, Paris, 2007, p. 325. Le texte original est en latin : je cite la traduction de J.-P. Grélois. Pierre Gilles a en particulier lu le texte grec intégral de l'Anaplus Bospori de Denys de Byzance ( $\mathrm{II}^{\mathrm{e}}$ siècle), dont la tradition manuscrite ne nous a conservé que le début et la fin : le milieu n'est connu que par sa traduction en latin.

$2 A P$, II. Les références ultérieures au texte seront faites simplement en citant les numéros des vers. Les traductions sont empruntées à P. WALtz dans Anthologie grecque tome I, Anthologie palatine livres I-IV, éd. et trad. P. Waltz, Paris, 1929 [désormais cité WALTZ] ; elles concernent avant tout l'aspect matériel des statues. 
l'essentiel des personnages mythologiques, des auteurs d'œuvres de l'esprit et des hommes d'État ${ }^{3}$. L'œuvre de Christodoros s'inscrit dans la tradition de l'ekphrasis ou description élaborée d'un objet. L'exemple le plus proche d'un tel ouvrage est bien sûr constitué par les Images de Philostrate (fin du II $^{\mathrm{e}}$ - début du III $^{\mathrm{e}}$ siècle). Ce dernier décrit en effet soixante-cinq tableaux censés appartenir à une galerie napolitaine : on ne peut savoir si celle-ci a réellement existé, mais le texte devait se caractériser par une certaine vraisemblance 4 . Sept personnages sont évoqués à la fois par Philostrate et Christodoros : Amymone, Hermès, Amphiaraos, Achille, Cassandre, Pindare et Héraclès. La comparaison est intéressante, même s'il s'agit de peintures dans le premier cas et de sculptures dans le second ${ }^{5}$. Le texte de Christodoros a fait l'objet en 2000 d'un commentaire approfondi de F. Tissoni ${ }^{6}$. En 2004, dans une étude des monuments de Constantinople dans l'Antiquité

3 On en trouvera la liste en annexe.

4 F. Lissarrague, “ Introduction », in Philostrate, La galerie de tableaux, trad. A. Bougot, Paris, 2013, p. 1-7, ici p. 4 [dans la note suivante, la pagination est empruntée à cette traduction].

5 Seule Amymone est représentée de manière comparable selon les deux textes, qui évoquent le moment où Poséidon lui apparaît, même si les détails diffèrent (Philostr. Jun., Im., I, 8, p. 22-23). Dans trois cas, l'iconographie rapportée par Philostrate n'est pas la même que celle évoquée par Christodoros. Ainsi, Hermès est figuré par le premier comme un enfant encore sur l'Olympe qui dérobe ses génisses et son arc à Apollon (Philostr. Jun., Im., I, 26, p. 51-52), alors que le second le représente occupé à nouer sa sandale. Pour Achille, l'éducation de l'enfant vêtu de la chlamyde dans un cadre bucolique (Philostr. Jun., Im., II, 2, p. 65-67) s'oppose à sa statue en guerrier adulte. Quant à Héraclès, il est évoqué après le meurtre du géant Antée, alors qu'il est endormi et assailli par les pygmées puis tandis qu'il se redresse et les enveloppe dans sa peau de lion (Philostr. Jun., Im., II, 22, p. 100-101), et, enfin, furieux après le meurtre de ses enfants, entouré par ses serviteurs qui tentent de l'enchaîner (Philostr. Jun., Im., II, 23, p. 101-103) ; par contraste, sa statue le figure imberbe tenant les pommes d'or des Hespérides. Enfin, dans trois autres cas, Philostrate décrit une scène précise, alors que Christodoros ne renvoie à aucune iconographie particulière. Ainsi, Amphiaraos, de retour de Thèbes, s'enfonce sous la terre dans son sanctuaire d'Oropos, monté sur son char, en armes, tandis que sa tête est couverte de bandelettes et de feuilles de laurier, c'est-à-dire qu'elle est consacrée à Apollon (Philostr. Jun., Im., I, 27, p. 52-53 - Christodoros évoque cependant sa couronne de laurier). Cassandre est représentée lors de son meurtre par Clytemnestre (Philostr. Jun., Im., II, 10, p. 80-81). Quant à Pindare, le poète enfant reçoit sur ses lèvres le miel versé par les abeilles (Philostr. Jun., Im., II, 12, p. 83-84).

6 F. Tissoni, Cristodoro. Un'introduzione e un commento, Alessandria, 2000 [désormais cité Tissoni]. Dans son commentaire (p. 89-256), l'auteur respecte l'ordre de présentation des statues par Christodoros de Coptos. 
tardive, S. Bassett ${ }^{7}$ s'est penchée sur la collection elle-même, mais sans utiliser le travail de F. Tissoni. À partir de ces deux ouvrages, il est possible d'étudier plus avant la signification de cette collection, en examinant à la fois la nature précise des statues et le contexte de l'édification du monument. Je voudrais ainsi d'abord revenir sur Christodoros de Coptos et sur les bains de Zeuxippe, deux préalables nécessaires à un réexamen de la collection. Je tenterai ensuite de proposer une interprétation qui prenne en compte les cultes païens de Byzance et la décoration de Constantinople sous Constantin, afin de dégager l'attitude du premier empereur chrétien à l'égard du patrimoine païen.

\section{Christodoros de Coptos}

Le livre II de l'Anthologie Palatine ${ }^{8}$ porte le titre suivant: “Du poète Christodoros, de Coptos en Thébaïde. Description des statues qui ornaient le

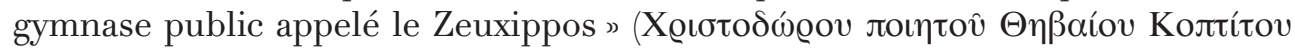

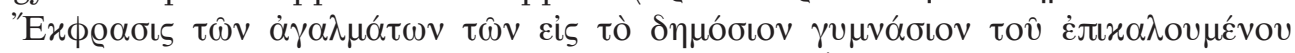

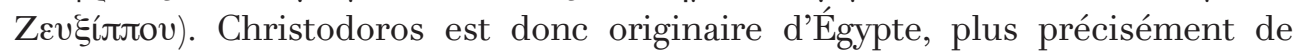
Coptos en Thébaïde, et il était actif sous Anastase I'r (491-518). En effet, le vers 405

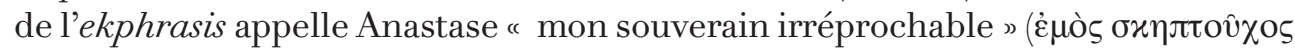
$\dot{\alpha} \mu v ́ \mu \omega v)$ et une scholie au vers 402 affirme que le poète a vécu sous Anastase. La Souda (dite aussi Suidas Lexicographus) ${ }^{9}$ donne la même indication. Cette notice de la Souda le qualifie en outre de fils de Paniscos et de poète épique (غ̇лолоьós). Elle lui attribue des Isaurika en 6 livres racontant la conquête de l'Isaurie par l'empereur Anastase, des Patria ${ }^{10}$ de Constantinople (12 livres), Thessalonique (25 livres), Naclè (cité proche d'Héliopolis ${ }^{11}$ ), Milet (en Ionie), Tralles et Aphrodisias.

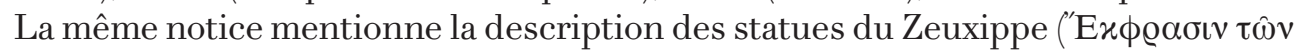

7 S. Bassett, The Urban Image of Late Antique Constantinople, Cambridge, 2004 [désormais cité BASSETT]. L’auteur a établi une prosopographie alphabétique des personnages représentés par les statues (p. 160-185). Lorsque je citerai cet ouvrage à propos d'une statue, je renverrai au numéro du personnage. L'ouvrage comporte par ailleurs la reproduction de quelques modèles statuaires.

8 Rappelons que ce nom est dû à un manuscrit grec originellement conservé à la Bibliothèque Palatine de Heidelberg, le Palatinus graecus 23, remontant selon toute probabilité à la seconde moitié du x $x^{\mathrm{e}}$ siècle.

9 Suid., X 525. Rappelons également que la Souda est une encyclopédie grecque du x ${ }^{\mathrm{e}}$ siècle.

10 C'est-à-dire des récits sur les origines.

1 Il s'agit donc d'une petite cité située en Égypte, patrie de Christodoros. 


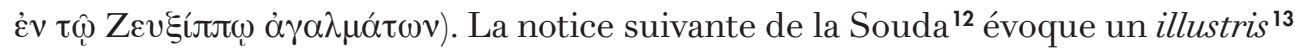
Christodoros de Thébaïde, auteur d'Ixeutica (traité de capture des oiseaux) et de Miracles des Saints Côme etDamien. Il est très probable qu'il faille attribuer les deux notices au même personnage. Au vi ${ }^{\mathrm{e}}$ siècle, Jean le Lydien ${ }^{14}$ parle d'un ouvrage en un livre du poète Christodoros intitulé Sur les auditeurs du grand Proclos. Une scholie à Homère évoque des Lydiaca d'un poète nommé Christodoros, qui doit encore être le même ${ }^{15}$.

On connaît aussi de Christodoros deux épigrammes ${ }^{16}$ sur la mort de Jean d'Épidamme ${ }^{17}$, gendre d'Anastase, lui-même également issu de cette cité. L'importance des Patria de Thessalonique (25 livres) dans l'œuvre de Christodoros doit être liée à ses relations avec Jean d'Épidamme, préfet du prétoire d'Illyricum, particulièrement estimé par les notables de la ville et son clergé, qui le sauvèrent des soldats goths ${ }^{18}$. En outre, un épisode du règne de Léon $\mathrm{I}^{\mathrm{er}}$ (457-474) renseigne sur le milieu dans lequel évoluait Christodoros. Malalas ${ }^{19}$ et la Chronique Pascale (a. 467) ${ }^{20}$ mentionnent le comes et médecin Iacobus ${ }^{21}$ à qui le Sénat de Constantinople éleva une statue dans les bains de Zeuxippe et que l'empereur

12 Suid., X 526.

13 C'est-à-dire un membre de la couche supérieure de l'ordre sénatorial.

14 Jean le Lydien, Des magistratures de l'État romain, III, 26, 3, trad. M. Dubuisson et J. Schamp, Tome II, Paris, 2006, p. 75.

15 J. Schamp, “Introduction générale », in Jean le Lydien, Des magistratures, Tome I, p. XIII-CXV, ici p. XXVI n. 48, l'identifie à Christodoros de Coptos en tant que spécialiste des Patria, et peut-être au poète objet de la notice de Suid., X 526.

16 AP, VII, 697-698.

17 J. Martindale, The Prosopography of the Later Roman Empire. Volume II, A. D. 395-527, Cambridge, 1980 [PLRE II] : Ioannes 29 [la graphie respecte l'usage de cet ouvrage pour désigner le rang sénatorial : illustris, SPECTABILIS, CLARISSIMVS] : né à Épidamme, consul en 467, maître des offices en 467/468, préfet du prétoire d'Illyricum en 479.

18 C. CAPIzZI, L'Imperatore Anastasio I (491-518). Studio sulla sua vita, la sua opera e la sua personalità, Rome, 1969, p. 206, relève l'ornement avec des sculptures zoomorphes par Anastase d'une église des Saints Côme et Damien à Épidamme (Georges Hamartolos,

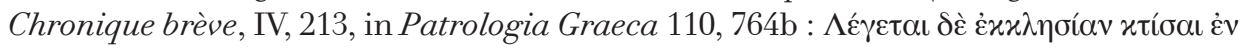

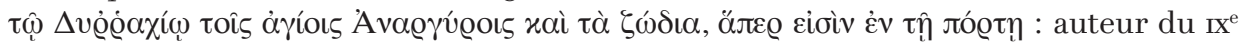
siècle). Comme l'a vu Tissoni, p. 25, c'est un argument supplémentaire pour identifier l'auteur des épigrammes sur Jean d'Épidamme (auteur par ailleurs objet de la notice de Suid. X 525) avec l'auteur de Miracles des Saints Côme et Damien, mentionné par la notice de Suid. X 526.

19 Malalas, Chronique, XIV, 38 [Ioannis Malalae Chronographia, éd. I. Thurn, Berlin-New York, 2000, p. 292-293].

20 Chronique Pascale, p. 595-596 [Chronicon paschale, éd. L. Dindorf, Bonn, 1832].

21 PLRE II : IACOBVS qui et PSYCHRISTVS 3. 
Léon I ${ }^{\mathrm{er}}$ tenait en grande estime. En 467, Iacobus intervint pour que le questeur païen Isocasius fût jugé par le préfet du prétoire, le consul Pusaeus. Or l'autre consul de cette année était Jean d'Épidamme, dont Christodoros a fait l'éloge. De plus, une autre statue de ce même Iacobus fut érigée à Athènes, où ce médecin fut en relation avec le chef de l'école néoplatonicienne Proclos, sur lequel Christodoros a aussi écrit. Il est donc probable que Christodoros connaissait bien Iacobus et que Jean d'Épidamme a joué un rôle dans l'érection d'une statue du personnage aux bains de Zeuxippe. Dès cette époque, Christodoros devait ainsi être intéressé par la collection du Zeuxippe, même si l'on ne peut retenir l'hypothèse de S. Bassett ${ }^{22}$, selon laquelle il aurait composé sa description à l'occasion de leur restauration et de la dédicace de nouvelles statues en 467. Enfin, une dernière épigramme ${ }^{23}$ est attribuable au même Christodoros : elle est consacrée à un bâtiment (oîxos) ${ }^{24}$ construit par Anastase, qualifié de « tueur d'Isauriens » ('Ioovooфóvov) de la même manière que dans le vers 399 de l'ekphrasis ${ }^{25}$.

Le texte qui nous occupe est en tout cas postérieur à la conclusion de la paix entre Anastase et les Isauriens en 498, évoquée aux vers 405-406. F. Tissoni ${ }^{26}$ a émis l'hypothèse qu'il ait pu être rédigé peu après 503, date assignable au panégyrique latin d'Anastase par Priscien de Césarée, qui évoque cet empereur comme un descendant de Pompée, de la même façon que les vers 403-404 de l'ekphrasis. Mais comme le panégyrique grec d'Anastase par Procope de Gaza (datant certainement des environs de 511, à l'occasion des Vicennalia de l'empereur ${ }^{27}$ ) ne mentionne pas cette généalogie, il faut rester circonspect sur l'influence de ces auteurs les uns sur les autres et donc sur ce moyen de datation ${ }^{28}$. Christodoros était probablement marqué par le néoplatonisme, comme le montre la tonalité de plusieurs de ses descriptions de statues, en particulier celle de Platon (rappelant

22 BASSETt, p. 52.

$23 A P, \mathrm{IX}, 656$.

24 Le lemma indique qu'il s'agirait de la Chalcè au grand palais, mais cette entrée monumentale remonte en fait à Constantin. On a probablement affaire au triklinos dit d'Anastase au palais des Blachernes, évoqué ainsi par la notice de Suid., A 2077, consacrée à cet empereur: "le même bâtit le grand triklinos situé aux Blachernes

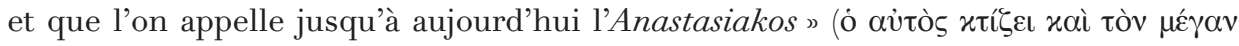

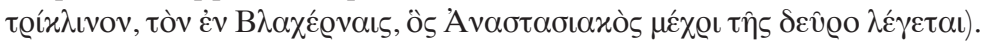
Tissoni, p. 30-36.

26 Idem, p. 22.

27 E. Амato, in Procope de Gaza, Discours et fragments, éd. et comm. E. Amato, A. Corcella et G. Ventrella, trad. P. Maréchaux, Paris, 2014, p. 245-246.

28 A. Kaldellis, "Christodoros on the Statues of the Zeuxippos Baths: A New Reading of the Ekphrasis », GRBS 47 (2007), p. 361-383, ici p. 379 ; le même auteur suggère que l'ekphrasis a pu être prononcée devant un public réuni dans les bains de Zeuxippe euxmêmes (p. 369). 
le vocabulaire de la Vie de Proclos par Marinos) et, bien sûr, l'existence de son ouvrage Sur les auditeurs du grand Proclos. Mais on doit rester prudent au sujet de l'appartenance religieuse de Christodoros, certainement auteur par ailleurs de Miracles des Saints Côme et Damien ${ }^{29}$. L'ekphrasis de Christodoros est une œuvre versifiée, qui cite abondamment Homère, dont la statue est de loin celle qui se trouve la plus longuement commentée. L'auteur s'inspire encore bien davantage du poète égyptien du v viècle Nonnos de Panopolis, surtout pour ses Dionysiaques mais aussi pour sa Paraphrase de l'Évangile selon saint Jean ${ }^{30}$. Pour conclure sur Christodoros, disons que son texte paraît bien constituer une description complète de la collection de statues anciennes du Zeuxippe. En effet, le vers 1 comporte la mention « le premier » ( reste pas moins que des statues de personnages contemporains ont été ajoutées dans l'Antiquité tardive : on a déjà vu le cas du médecin Iacobus ${ }^{31}$.

\section{Les bains de Zeuxippe}

La construction initiale des bains de Zeuxippe est attribuée à Septime Sévère par Malalas, Jean le Lydien ${ }^{32}$ et plusieurs auteurs byzantins postérieurs. A.-V. Pont a montré que l'on pouvait avoir des doutes à ce sujet, tant Septime Sévère constitue à bien des égards une figure mythique pour une Constantinople en quête de ses origines ${ }^{33}$. On note en particulier que des bains furent créés à Nicomédie sous Caracalla puis restaurés sous Dioclétien, qui y fit aussi construire un hippodrome. Ainsi, Malalas, Jean le Lydien et les auteurs byzantins postérieurs semblent bien opérer « un dépouillement symbolique de Nicomédie au profit de Byzance », afin d'ancrer Constantinople dans un passé prestigieux (et alors que Nicomédie avait été la capitale de Dioclétien) ; il faut préciser que Byzance a résisté à Septime

29 Tissoni, p. 37-44, évoque le fait que Zosime, historien farouchement défenseur du paganisme, a écrit à la même époque d'Anastase. Mais les véritables pratiquants du paganisme étaient alors extrêmement rares, surtout dans l'entourage impérial. L'épisode mentionné à propos du règne de Léon $\mathrm{I}^{\mathrm{er}}$, quelques décennies auparavant, révèle à quel point ils étaient pourchassés, avant même la politique radicale de Justinien $\mathrm{I}^{\mathrm{er}}(527-565)$.

30 Idem, p. 66. L'existence de ces deux œuvres très différentes de Nonnos montre qu'il est très difficile de se prononcer sur son appartenance religieuse, de la même manière que pour Christodoros.

31 Wattz, p. 53, évoque aussi la statue de “ l'hérésiarque Philippikos » mais il s'agit d'une confusion avec le dernier empereur attesté dans l'activité des bains de Zeuxippe, Philippikos Bardanès (711-713), qui était partisan du monothélisme, doctrine considérée comme hérétique.

32 Malalas et Jean le Lydien ont écrit au vi ${ }^{\mathrm{e}}$ siècle.

33 A.-V. Pont, "Septime Sévère à Byzance : l'invention d'un fondateur », AntTard 18 (2010), p. 191-198, ici p. 194-196. 


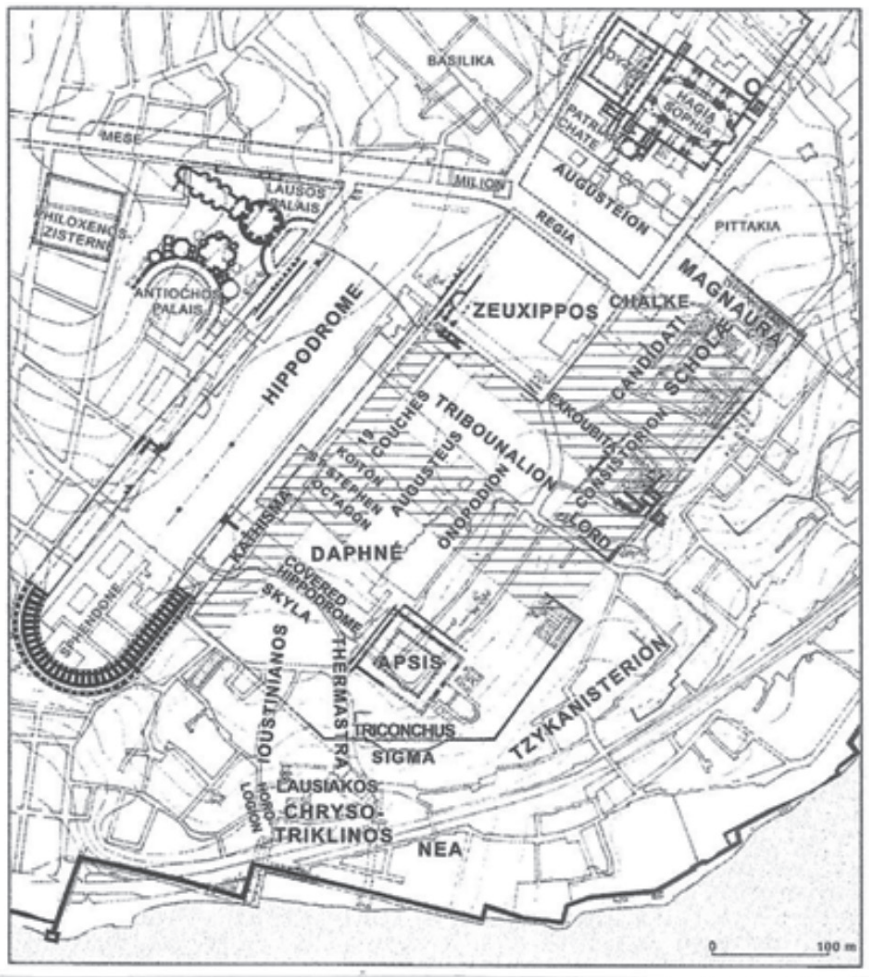

Fig. 1 : Localisation des bains de Zeuxippe. E. Bolognesi RecchiFranceschini et M. Featherstone, “ The Boundaries of the Palace: De ceremoniis II, 13 », Travaux et Mémoires 14 (2002), p. 46.

Sévère puis a été prise par lui lors de la guerre civile contre Pescennius Niger, ce qui ne favorisait pas les interventions édilitaires du fondateur de la dynastie sévérienne. En outre, les monnaies retrouvées sur le site et les briques timbrées des bains de Zeuxippe n'attestent aucune activité antérieure à 330 dans ce secteur, situé entre la Chalcè (entrée monumentale) du grand palais et les carceres (portes de départ) de l'hippodrome (fig. 1) ${ }^{34}$. Faute de preuves suffisantes à propos de Septime Sévère, il faut donc admettre que Constantin fut le bâtisseur des bains de Zeuxippe, de la même manière qu'il fut celui de la Chalcè, mais aussi de l'hippodrome (également attribué de façon douteuse à son prédécesseur).

Le nom de “Zeuxippe » est difficile à interpréter ${ }^{35}$. Selon Malalas, “ [Septime Sévère] construisit un bain public appelé Zeuxippe car une statue de bronze d'Hélios (le soleil) se trouvait là au milieu du Tétrastôon. Sur sa base était inscrit le nom mystique du soleil : “Au dieu Zeuxippos» car c'est ainsi que les Thraces nommaient le soleil. Ainsi le peuple de la cité de Byzas avait l'habitude d'appeler le bain public Zeuxippe d'après le nom originel du lieu » ${ }^{36}$. Sur le plan étymologique,

34 J. Bardill, Brickstamps of Constantinople, Oxford, 2004, p. 68.

35 Voir en dernier lieu Tissoni, p. 75.

36 Malalas, Chronique, XII, 20, p. 221. 


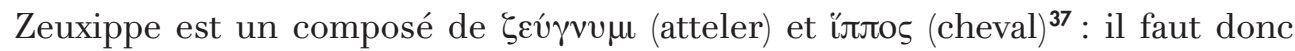
simplement y voir un attelage de chevaux et certainement une allusion au char du soleil, et ne pas s'égarer avec les étymologies tardives telles que « Zeus Hippios ». Mais dans la Grèce classique Zeuxippe est un nom de personne, attesté chez Platon $^{38}$ et Xénophon ${ }^{39}$. C'est ainsi que Pausanias ${ }^{40}$ affirme que le dernier roi de Sicyone fut Zeuxippe, fils d'Apollon et de la nymphe Syllis. Jean le Lydien évoque “ l'agora que l'on appelle le Zeuxippe, d'après le roi Zeuxippos, sous le règne de qui, au cours de la 38 olympiade [vers 628 av. J.-C.], les Mégariens colonisateurs de Byzance avaient donné son nom à l'agora pour lui faire honneur „41. Dans sa dissertation latine sur Christodoros rédigée à la fin du $\mathrm{xIx}^{\mathrm{e}}$ siècle, $\mathrm{F}$. Baumgarten avait tenté de concilier les données de Pausanias et Jean le Lydien. Il avançait que les colons mégariens de Byzance avaient fondé un culte public d'Apollon Sol Zeuxippos en souvenir du roi mythique de leur patrie ${ }^{42}$. On peut penser, plus prudemment, que l'indication de Jean le Lydien s'apparente à une reconstruction savante à partir du mythique roi de Sicyone ou Mégare, et de l'assimilation d’Apollon à Hélios. La donnée à peu près assurée est que le nom de Zeuxippe est lié à un culte solaire apollinien, quelle que soit son origine exacte $\mathrm{e}^{43}$.

À propos du rôle du fondateur de Constantinople, Malalas apporte des éléments précis : “[Constantin] acheva aussi le bain public appelé Zeuxippe,

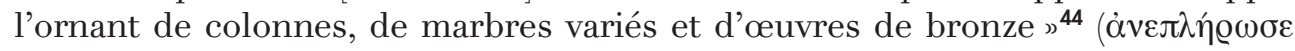

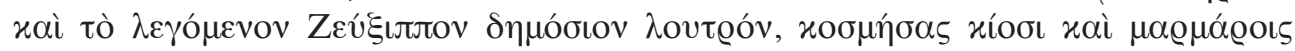

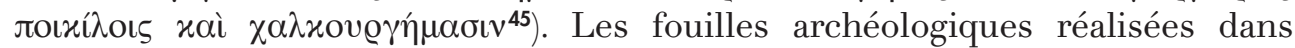
le secteur apportent à ces données quelques confirmations et révèlent aussi

37 G. DAGron, Naissance d'une capitale. Constantinople et ses institutions de 330 à 451, Paris, 1974, p. 368-369.

38 Pl., Prt., 318b.

$39 \mathrm{X} ., H G, 2,3,10$.

40 Paus., II, 6, 7 (après sa mort de ce Zeuxippos, Sicyone fut conquise par Agamemnon).

41 Jean le Lydien, Des magistratures, III, 70, 4, p. 133. A. Rовu, Mégare et les établissements mégariens de Sicile, de la Propontide et du Pont-Euxin. Histoire et institutions, Berne, 2014, p. 283, indique qu'il n'y a pas de raisons de rejeter une fondation de Byzance par Mégare en 659/658 (date fournie par la Chronique d'Eusèbe de Césarée), mais qu'une nouvelle vague de colons est peut-être arrivée vers 628 ; pour lui, le chef des colons mégariens a pu effectivement être le basileus Zeuxippos.

42 F. Baumgarten, De Christodoro poeta Thebano, Bonn, 1881, p. 12-13.

43 Selon J. Christien-Trégaro, “ Les Péloponnésiens et la mer Noire », in O. Lordkipanidzé et P. LÉvêQue éd.), Sur les traces des Argonautes, Paris, 1996, p. 146-147, le culte d'Hélios à Byzance aurait une origine corinthienne (Hélios était honoré par un autel sur l'Acrocorinthe).

44 Trad. J.-Cl. Cheynet, Byzance. L'Empire romain d'Orient, Paris, 2015, p. 176.

45 Malalas, Chronique, XIII, 8, p. 246. 
des aspects nouveaux ${ }^{46}$. On a retrouvé des fragments de revêtements muraux composés de marbres d'origine africaine de diverses couleurs (verde antico, rosso, giallo $)^{47}$, ainsi que des bases inscrites de statues d'Eschine et Hécube ${ }^{\mathbf{4 8}}$. Dans la topographie du site, le monument I comprend des restes de canalisations et se composait donc des bains, tandis que le monument II inclut un ample péristyle et une salle octogonale ${ }^{49}$ et s'interprète comme un gymnase ${ }^{50}$. On sait que les bains de Zeuxippe ont été détruits en 532 lors de la révolte $\mathrm{Nika}^{51}$. Le monument a été reconstruit par Justinien ${ }^{52}$ mais la collection de statues avait été irrémédiablement perdue. La dernière attestation du bâtiment dans sa fonction thermale remonte à 713, avec le bain pris par la cour de l'empereur Philippikos Bardanès ${ }^{53}$.

L'existence matérielle des statues décrites par Christodoros a donc été directement prouvée, on l'a vu, par la trouvaille de deux bases inscrites, celles d'Eschine et Hécube. De manière indirecte, elle peut aussi être confirmée par la connaissance de statues (ou autres représentations) similaires des personnages concernés. F. Tissoni a accompli une importante recherche iconographique, en particulier par le recours au Lexicon Iconographicum Mythologiae Classicae $(L I M C)$, et je me bornerai ici à relever, à sa suite, les seules seize comparaisons évidentes qui s'imposent, sur un total de soixante-dix représentations. Les plus nombreuses (dix) concernent les figures mythologiques. Déiphobe ${ }^{54}$ se trouve sur des vases grecs où il est représenté comme un hoplite en mouvement avec un casque, une épée à la main droite et un bouclier à la gauche ${ }^{55}$. Amymone et

46 S. Casson, D. Talbot Rice et D. Hudson, Second Report upon the Excavations Carried Out in and near the Hippodrome of Constantinople in 1928, Londres, 1929.

47 Idem, p. 9-10.

48 Ibidem, p. 235 : les statues de ces deux personnages font partie de celles qui sont décrites par Christodoros.

49 Dans cette salle octogonale, on a retrouvé un relief avec une Néréide et un dauphin. Cette salle est mentionnée par Kedrènos, auteur byzantin du xis ${ }^{\mathrm{e}}$ siècle qui a parlé du Zeuxippe, comme on va le voir.

50 Ibidem, p. 231. Christodoros était donc fondé à évoquer un gymnase, même si l'on ne peut exactement savoir où étaient installées les statues.

51 Kedrènos, Histoire, I, p. 647-648 [Georgius Cedrenus, éd. I. Bekker, 2 volumes, Bonn, 1838-1839].

52 Procop., Aed., I, 10, 3.

53 Théophane, Chronographie, p. 383 [Theophanis chronographia, éd. C. de Boor, Leipzig, 1883-1885].

54 Déiphobe (1-12) : “Déiphobe, le premier, sur un socle orné de belles ciselures, se tenait debout, le casque en tête (...) tel qu'au jour où il se rencontra avec l'impétueux Ménélas, au seuil de son palais en ruines (...) de la main gauche, il élevait devant lui un large bouclier, tandis que de la main droite il brandissait son épée ».

55

Tissoni, p. 89. LIMC, III. 1, p. 362-367. 
Poséidon ${ }^{56}$ peuvent être figurés respectivement assise et debout, en particulier sur un vase et une monnaie ${ }^{57}$. Apollon ${ }^{58}$ est représenté selon l'iconographie de sa fameuse statue du Belvédère ${ }^{59}$. L'une des représentations d'Aphrodite ${ }^{60}$ relève aussi d'un type célèbre, représenté par la Vénus de Milo ${ }^{61}$. Hermaphrodite ${ }^{62}$ rappelle une statue en marbre conservée à Berlin ${ }^{63}$. Héraclès ${ }^{64}$ a pu être figuré jeune en tenant les pommes d'or du jardin des Hespérides ${ }^{65}$. Ménélas et Hélène ${ }^{66}$ sont représentés lors de leur réconciliation sur de nombreux vases ${ }^{67}$. Achille ${ }^{68}$ relève d'un type proche du doryphore de Polyclète ${ }^{69}$. Hermès ${ }^{70}$ est figuré comme

56 Amymone et Poséidon (61-68) : “ Amymone aux doigts de rose était assise ; elle avait noué derrière sa tête les boucles de ses cheveux, que ne retenait aucun bandeau ; elle avait le front découvert et levait les yeux pour regarder venir son époux, le dieu marin à la noire chevelure. Tout près d'elle se montrait la large poitrine du dieu aux cheveux sombres ; il était nu, il laissait flotter librement les boucles de sa chevelure et il tendait le dauphin tout ruisselant d'eau qu'il portait dans sa main, comme présent nuptial pour la jeune fille dont tant de prétendants recherchaient l'hymen ».

57 Tissoni, p. 114. LIMC, I. 1, p. 747-748 (n 75 : vase d'Italie du Sud vers 330 av. J.-C. ; $\mathrm{n}^{\circ} 76$ : monnaie d'Argos sous Antonin le Pieux).

58 Apollon (72-77) : « Phébus était debout (...) avait serré par derrière les tresses dénouées de sa chevelure ; mais le bronze le montrait tout nu (...) car c'est le soleil que ce dieu Phébus et pur est l'éclat des rayons qu'il lance au loin ».

59 Tissoni, p. 120 ; LIMC, II. 1, p. 244-245. L’Apollon dit du Belvédère est conservé au musée Pio Clementino du Vatican.

60 Aphrodite (78-81) : « Elle laissait voir son sein nu ; mais elle retenait les plis de sa robe sur la rondeur de ses cuisses et ses boucles étaient serrées dans un voile d'or ».

${ }_{61}$ Tissoni, p. 123 : LIMC, II. 1, p. 63 (Aphrodite d'Arles) ; p. 65 (Aphrodite d'Ostie) ; p. 73 (Vénus de Milo).

62 Hermaphrodite (102-107) : la statue a les seins gonflés et un sexe masculin.

63 Tissoni, p. 131. LIMC, V. 1, p. 271 (n 5 : statue en marbre de Berlin).

64 Héraclès et Augê (136-143) : “ Héraclès montrait l'orbe de son menton imberbe, portant dans sa main qui tua le lion les pommes d'or, somptueux présent de la terre libyenne».

65 Tissoni, p. 148. LIMC, IV. 1, n 380 (statue du Louvre).

66 Ménélas et Hélène (165-170) : “On pouvait voir le guerrier Ménélas, mais, lui, tout heureux de sa victoire : il brûlait d'une joie ardente en voyant près de lui la fille de Tyndare aux bras de rose, qui répondait à ses sentiments ».

67 Tissoni, p. 158. LIMC, IV. 1, p. 498-563.

68 Achille (292-296) : “guerrier imberbe (...) Il était sans armure; mais il avait l'air de brandir une pique de la main droite et, de la gauche, de lever un bouclier de bronze ».

69 Tissoni, p. 205. LIMC, I. 1, p. 196 (n 908). Le doryphore de Polyclète (ve siècle av. J.-C.) a été identifié à Achille par Pline l'Ancien.

70 Hermès (297-302) : “ Hermès à la baguette d'or ; de sa main droite, il resserrait les liens de sa chaussure ailée ; prêt à s'élancer pour se mettre en route, il tenait déjà pliée sa rapide jambe droite, tandis que son bras gauche s'appuyait sur elle et qu'il levait les yeux vers le ciel ». 
sur la fameuse statue où il attache sa sandale ${ }^{71}$. Artémis ${ }^{72}$ rappelle aussi une statue comme la Diane de Versailles ${ }^{73}$. Viennent ensuite deux orateurs fameux par leur opposition, Eschine ${ }^{74}$ et Démosthène ${ }^{75}$. On relève aussi deux hommes d'État célèbres, Alcibiade ${ }^{76}$ et Jules César ${ }^{77}$. Enfin, Pythagore ${ }^{78}$ et Homère $^{79}$ trouvent peut-être quelque écho dans des représentations connues.

71 Bassett, n 63. LIMC, V. 1, p. 368 (n 958a : statue du III ${ }^{\mathrm{e}} / \mathrm{II}^{\mathrm{e}}$ siècle av. J.-C. conservée à Copenhague).

72 Artémis (306-310) : “ elle avait retroussé jusqu'aux genoux sa tunique virginale garnie de franges et abandonnait aux brises les boucles de sa chevelure sans bandeau ».

73 Tissoni, p. 212 : Christodoros imite Callimaque, qui lui-même devait avoir vu une statue du type de la Diane de Versailles (Iv siècle av. J.-C.).

74 Eschine (13-16) : “il contractait l’orbe de ses joues hérissées de barbe, était tendu » (selon Waltz, p. 62 n. 1, il avait la bouche ouverte). Tissoni, p. 94-95: Eschine était probablement représenté par une statue à la barbe et aux joues creuses, issue de la villa des Papyri à Herculanum et conservée au Musée National de Naples ; il existe aussi un buste barbu à la glyptothèque Ny Carlsberg de Copenhague.

75 Démosthène (23-31). Tissoni, p. 97-98 : la statue en bronze installée sur l'agora d'Athènes en 280/279 et réalisée par Polyeucte est le prototype des statues de marbre de Démosthène, en particulier celle de la glyptothèque Ny Carlsberg de Copenhague.

76 Alcibiade (82-85). Tissoni, p. 124 : cette statue semble proche d'un Alcibiade jeune aux cheveux longs et imberbe présent sur une mosaïque de Sparte d'époque romaine ou sur un relief inscrit d'Aphrodisias.

77 Jules César (92-96): “Il rassemblait sur son épaule les plis de l'égide terrible à regarder » (selon WaLtz, p. 65 n. 1, il s'agit du geste de la Diane de Gabies); “ et de sa main droite il brandissait fièrement la foudre, ce héros que les Ausoniens appellent un second Jupiter ». Tissonı, p. 127-128 : sur une statue fragmentaire de César (conservée à Copenhague), la cuirasse comporte la Méduse, dont l'épithète homérique est « terrible

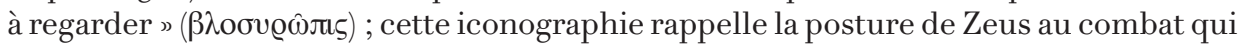
utilise l'égide comme bouclier et la foudre comme lance, selon Nonnos de Panopolis (Nonn., D., II, 469-480).

78 Pythagore (120-124): “ le sage de Samos ». Bassett, n 88 : la numismatique de Samos à l'époque romaine montre Pythagore drapé et barbu.

79 Homère (311-350) : «Sur le cou incliné du vieillard pendaient les boucles de sa chevelure, rejetées en arrière et flottant librement autour de ses oreilles ; sa barbe descendait, souple et légère, s'élargissant et s'étalant; elle n'était pas taillée en pointe, mais elle se répandait largement (...) Quant à ses deux sourcils, l'artiste ingénieux les avait sculptés en saillie, non sans raison, car ses yeux étaient privés de la lumière (...) Ses deux joues se creusaient légèrement (...) Les deux mains posées l'une sur l'autre, il s'appuyait sur un bâton (...) il penchait l'oreille droite ». Selon WALTz, p. 76 n. 2, la position des mains et le bâton rappellent exactement l'attitude de la statue d'Homère conservée à Naples. D'après Tissoni, p. 225, le bâton n'est pas nécessairement un élément d'identification de la statue, car il est d'abord l'instrument des rhapsodes, accompagnant la récitation de vers épiques. 


\section{La collection}

Si l'on considère l'ensemble de la collection, Christodoros décrit sept groupes de statues (Amymone et Poséidon; Héraclès et Augê ; Énée et Créuse ; Pyrrhos et Polyxène ; Oenone et Pâris ; Darès et Entelle ; Panthoos, Thymétès, Lampon et Clytios). Par ailleurs, plusieurs termes expriment la proximité entre deux statues ${ }^{80}$. On est donc depuis longtemps arrivé à l'idée que le poète décrivait correctement la place des statues dans la collection. Cette constatation n'a pas manqué de susciter des tentatives d'interprétation. La plus systématique est celle de R. Stupperich ${ }^{81}$, qui a proposé de classer les statues en cinq ensembles thématiques selon l'ordre de leur exposition (de Déiphobe à Hésiode ; d'Amymone et Poséidon à Héraclès et Augê ; d'Énée et Créuse à Hécube ; de Darès et Entelle à Artémis ; d'Homère à Virgile). Cette hypothèse a été à juste titre réfutée par $\mathrm{S}$. Bassett ${ }^{82}$, qui montre bien que ces ensembles manquent de cohérence. Quelques regroupements ont visiblement été opérés, mais l'ordre général est plutôt aléatoire et mieux vaut donc repérer quelques grands types de personnages dans l'ensemble de la collection ${ }^{83}$.

Parmi les cinq divinités présentes (Apollon, Aphrodite, Artémis, Hermès et Poséidon), deux (Apollon et Aphrodite) sont représentées chacune par trois statues. Apollon est systématiquement figuré selon un type jeune à la longue chevelure $^{84}$. Aphrodite répond, elle, à des types différents, où elle est de moins

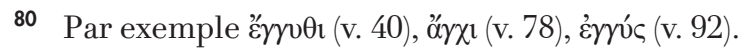

81 R. Stupperich, “ Das Statuenprogramm in den Zeuxippen-Thermen. Überlegungen zur Beschreibung durch Christodoros von Koptos ", Istanbuler Mitteilungen 32 (1982), p. 210-235.

82 S. Guberti Bassett, "Historiae custos: Sculpture and Tradition in the Baths of Zeuxippos ", American Journal of Archaeology 100/3 (1996), p. 491-506.

83 En ce qui concerne la mythologie classique, je renvoie une fois pour toutes aux notices de P. Grimal, Dictionnaire de la mythologie grecque et romaine, Paris, 1951, pour les références aux auteurs anciens.

84 Apollon (72-77) (BASSETt, $n^{\circ}$ 41) : “ Phébus était debout (...) avait serré par derrière les tresses dénouées de sa chevelure; mais le bronze le montrait tout nu (...) car c'est le soleil que ce dieu Phébus et pur est l'éclat des rayons qu'il lance au loin »; Apollon (266-270) (BASSETT, n 42) : “ Le souverain maître du chant. Sa chevelure s'ornait d'une libre floraison de festons; sur ses deux épaules tombaient en se divisant ses boucles naturellement frisées. Il roulait des regards divinateurs, comme s'il eût voulu, par ses oracles, délivrer les mortels de leurs maux »; Apollon (283-287) (Bassett, n 43) : “ le dieu à la belle chevelure, qui rend des oracles sur son trépied (...) ses boucles frisées ruisselaient sur ses deux épaules ». 
en moins dénudée si l'on suit l'ordre de l'ekphrasis ${ }^{85}$. Artémis ${ }^{86}$, sœur d'Apollon, est représentée dans le costume traditionnel de la déesse chasseresse ${ }^{87}$, avec une coiffure qui rappelle celle de son frère. Hermès ${ }^{88}$, on l'a vu, est figuré selon le type classique à la sandale. Enfin, Poséidon est représenté en compagnie de son amante mortelle, Amymone ${ }^{89}$. Or il est manifeste que ces cinq divinités sont celles qui endossent les premiers rôles dans la légende de Troie. Apollon est véritablement le dieu à l'origine de la guerre de Troie, comme instigateur de la querelle entre Agamemnon et Achille. Il est le grand défenseur de Troie, le protecteur de Pâris et le responsable de la mort d'Achille. Sa sœur Artémis envoya un calme qui paralysa la flotte grecque en partance pour Troie (à la suite d'une offense d'Agamemnon prétendant avoir tué un cerf à la chasse mieux qu'elle ne l'aurait fait) : les Grecs voulurent lui sacrifier la fille d'Agamemnon Iphigénie, mais elle lui substitua une biche. Aphrodite est, elle aussi, à l'origine de la guerre de Troie : choisie par Pâris, elle lui accorda la main d'Hélène ; elle est également la mère d'Énée. Notons qu'Apollon, Aphrodite et Artémis sont les principaux dieux favorables aux Troyens : ce n'est pas un hasard si les deux premiers sont largement représentés dans la collection, tandis que la troisième pouvait passer pour une auxiliaire de son frère. Hermès a lui aussi un rôle initiateur dans la légende troyenne, en conduisant Héra, Aphrodite et Athéna devant Pâris pour qu'il soit leur juge. De plus, Hermès est fortement lié à Apollon. Il a dérobé ses troupeaux à Apollon, qui a renoncé finalement à les lui réclamer en obtenant de lui le don de sa lyre ; en outre, la baguette d'or, ou caducée, a été donnée à Hermès par Apollon, en échange d'un autre instrument de musique, la flûte ${ }^{90}$. Enfin, rappelons que Troie se trouva en deuil en raison de la colère d'Apollon et de Poséidon, car les deux dieux avaient construit les murailles mais n'avaient pas reçu le salaire convenu : le premier envoya à la ville une peste et le second un monstre marin ; par vengeance, Poséidon fut favorable aux Grecs pendant la guerre de Troie, à laquelle il restait cependant lié par sa muraille.

85 Aphrodite (78-81) (BASSETT, $\mathrm{n}^{\circ}$ 38) : “ Elle laissait voir son sein nu ; mais elle retenait les plis de sa robe sur la rondeur de ses cuisses et ses boucles étaient serrées dans un voile d'or »; Aphrodite (99-101) (BAssett, n 39) : “ se montrait dans sa nudité resplendissante ; sur sa poitrine seulement, en s'y répandant depuis le haut de sa gorge, s'enroulait le ceste »; Aphrodite (288-290) (BASSETt, n 40) : " un manteau voilait sa poitrine ; autour de ses seins, le ceste s'enroulait mollement ». Le ceste est une bande d'étoffe (WaLtz, p. 65 n. 5$)$.

86 Artémis (306-310) (BAssETt, n 46) : “ elle avait retroussé jusqu'aux genoux sa tunique virginale garnie de franges et abandonnait aux brises les boucles de sa chevelure sans bandeau ".

87 WaLtz, p. 125.

88 Hermès (297-302) (BASSETt, $n^{\circ}$ 63).

89 Amymone et Poséidon (61-68) (Bassetr, n 85$)$.

90 Signalons aussi la présence d'Hermaphrodite (102-107) (BASSETt, n 62), qui passait pour le fils d'Hermès et d'Aphrodite, et qui était fréquemment représenté dans les thermes. 
Il n'est pas nécessaire d'insister sur le fait que les trois principaux dieux représentés, ceux qui sont favorables aux Troyens, jouent un rôle essentiel dans les origines de Rome, dont les mythes furent revivifiés à l'époque augustéenne. Aphrodite et Énée sont les ancêtres de la gens Iulia. Apollon fut particulièrement vénéré par Auguste, en particulier comme responsable de la victoire d'Actium, et fut doté d'un temple sur le Palatin communiquant avec la domus impériale ${ }^{91}$. Artémis ou Diane, prisée par Livie, fut gratifiée d'un nouveau temple sur l'Aventin ${ }^{92}$. Dans le Chant séculaire d'Horace, Apollon et Artémis sont les divinités intermédiaires entre le peuple romain et Jupiter, elles transmettent les bénédictions célestes. Il est donc clair dès l'abord que la collection s'inspire de la mythologie troyenne et apollinienne propre aux origines de l'Empire romain.

Vingt-et-une représentations relèvent strictement de la légende troyenne, soit la quasi totalité des figures mythologiques, ce qui renvoie bien sûr à la thématique de Constantinople comme Nouvelle Rome. Parmi ces vingt-et-un groupes de personnages, treize appartiennent au camp des Troyens, soit les deux tiers, ce qui s'explique par le fait qu'ils étaient considérés comme les ancêtres des Romains $^{93}$. Il s'agit ainsi de Déiphobe ${ }^{94}$; Chrysès $^{95}$; Énée et Créuse ${ }^{96}$; Hélénos ${ }^{97}$;

91 F. Coarelli, Guide archéologique de Rome, trad. R. Hanoune, Paris, 1994, p. 98-99.

92 Idem, p. 233.

93 BAssett, 2004, p. 53, avait remarqué que la majorité des personnages renvoyait au moment de la chute de Troie.

94 Déiphobe (1-12) (Bassett, n 51). Il a épousé Hélène après la mort de Pâris puis fut tué par Ménélas lors de la prise de Troie (Waltz, p. 61 n. 1).

95 Chrysès (86-91) (BAssetr, $n^{\circ}$ 49) : “ tenant dans sa main droite le sceptre de Phébus et portant sur sa tête une couronne (...) une barbe fleurie descendait sur sa poitrine et l'on voyait pendre les boucles éparses de sa longue chevelure »; prêtre d'Apollon, il adresse sa prière au fils d'Atrée [Agamemnon]. Selon Il., I, 373-374, il est « muni de son sceptre d'or coiffé des bandelettes de l'archer Apollon ». Chrysès est le prêtre d'Apollon de la ville de Chrysè en Troade ; il est le père de Chryséis enlevée par les Grecs et donnée à Agamemnon comme part de butin ; comme ce dernier refuse de la rendre, Chrysès prie Apollon d'envoyer une peste, ce qui contraint Agamemnon à la restituer.

96 Énée et Créuse (143-154) (BAssetr, n 27): “Sois-nous propice, rejeton de la terre troyenne, dont le bras brandit un bouclier ; sois-nous propice, Énée, illustre conseiller des Troyens (...) la progéniture d'Aphrodite (...) [Créuse] avait ramené son voile jusque sur ses deux joues et enveloppé tout son corps d'un manteau qui lui tombait jusqu'aux pieds (...) Les larmes de bronze que versait la jeune femme annonçaient que Troie, qui l'avait nourrie, avait succombé sous les coups d'Arès, vaincue par les Argiens armés de boucliers ». Créuse est la fille de Priam et d'Hécube. Selon Virgile, Énéide, II, 736 suiv., elle fut enlevée par Cybèle (ou Aphrodite selon d'autres versions) pendant qu'Énée quitte la ville : son ombre apparaît à ce dernier et lui prédit ses voyages.

97 Hélénos (155-159) (Bassetr, $n^{\circ} 59$ ): “Dans sa main droite, il élevait une coupe à libations ; à ce que je suppose, il prédisait des succès aux Argiens et priait les dieux de faire paraître les ultimes présages annonçant la ruine de la ville qui l'avait nourri ». 
Andromaque $^{98}$; Hélène ${ }^{99}$; Hécube ${ }^{100}$; Cassandre ${ }^{101}$; Polyxène ${ }^{102}$; Oenone et Pâris ${ }^{103}$; Darès et Entelle ${ }^{104}$; Panthoos, Thymétès, Lampon et Clytios ${ }^{105}$;

Après la mort de Pâris, Hélénos avait convoité la main d'Hélène, mais il avait été évincé par Déiphobe ; jaloux, il aurait révélé aux Grecs les conditions que le destin avait mises à la chute de Troie (Waltz, p. 68 n. 2).

98 Andromaque (160-164) (Bassett, $\left.\mathrm{n}^{\circ} 37\right)$.

99 Ménélas et Hélène (165-170) (BASsETt, n 74 et 58). Il s'agit de la réconciliation d'Hélène et de Ménélas après la prise de Troie (Waltz, p. 68 n. 3).

100 Hécube (175-188) (BAssett, n 75) : “ Hécube infortunée, qui des immortels t’a enseigné à verser des larmes jusque sous la forme d'une statue muette? (...) sur la ruine de ta patrie (...) le voile qui entoure ton visage témoigne de tes malheurs et tes vêtements qui pendent révèlent la profondeur de ta souffrance »

101 Cassandre (189-191) (Bassett, $n^{\circ}$ 70). Priam avait fait enfermer sa fille Cassandre dans une tour, pour l'empêcher de troubler la ville par ses sinistres prophéties, dès le jour où Pâris était parti pour enlever Hélène à Lacédémone (WALTz, p. 69 n. 4).

102 Pyrrhos (Néoptolème) et Polyxène (192-208) (Bassett, n 87) : “ [Pyrrhos] brillait nu, le menton sans barbe ; il élevait la main droite en signe de victoire, tout en jetant un regard de côté sur Polyxène éplorée (...) Dis-moi Polyxène, vierge infortunée, quelle douleur te contraint, jusque dans le bronze muet, à verser secrètement des larmes? Pourquoi ramènes-tu ton voile sur ton visage et te tiens-tu debout, dans cette attitude pudique, tandis que ton cœur est en proie au chagrin? ». Le geste de Pyrrhos consiste peut-être à vouer Polyxène aux dieux infernaux (Waltz, p. 69 n. 6). Christodoros reprend la légende (très répandue à l'époque impériale mais inconnue dans la Grèce classique) de l'amour d'Achille pour Polyxène et de sa mort dans une sorte de guetapens tendu par Pâris, avant que Pyrrhos (fils d'Achille) n'égorge la jeune fille pour la sacrifier aux mânes de son père (WALtz, p. 70 n. 1 et 2). L'égorgement de Polyxène près du tombeau d'Achille fut représenté dans la Pinacothèque des Propylées de l'Acropole (Tissoni, p. 167). Polyxène est la plus jeune fille de Priam et Hécube ; son sacrifice (alors qu'elle était mortellement blessée pendant la prise de Troie) est, dans certaines versions, indépendant de l'histoire de ses amours avec Achille.

103 Oenone et Pâris (215-221) (BAssett, n 76) : “ elle adressait de secrètes menaces, en le repoussant de la main, à son malheureux époux. Quant au berger, il semblait confus et détournait son regard errant ». Oenone avait été la femme de Pâris, qui la répudia pour épouser Hélène. Blessé à mort par Philoctète, Pâris ne pouvait être sauvé que par un remède connu de la seule Oenone ; elle reste sourde à ses supplications, mais se jette ensuite sur son bûcher funèbre (WaLtz, p. 124).

104 Darès et Entelle (222-227) (BAssETt, n ${ }^{\circ}$ 50) : « Darès s'entourait les mains de lanières en cuir desséché [ceste] (...) Entelle, de son côté, dardait droit sur Darès un regard irrité ». D'après Virgile, Énéide, V, 362-484, ce sont deux pugilistes qui combattent lors des jeux funèbres en l'honneur d'Anchise ; Darès est le seul rival attitré de Pâris. Tissoni, p. 178, remarque que sa statue figure justement à côté de celle de Pâris.

105 Panthoos, Thymétès, Lampon et Clytios (246-255) (BAssetr, $\left.n^{\circ} 78\right)$. Ces quatre personnages sont des Anciens de Troie qui accompagnent Priam sur les remparts d'où il assiste aux combats et lui délivrent de sages conseils ; Lampon est le nom retenu par 
Sarpédon ${ }^{106}$. Le choix de ce dernier est certainement lié au fait qu'Apollon était considéré comme un dieu d'origine lycienne ${ }^{107}$. Onze représentations du cycle de Troie, soit le tiers des personnages, sont composées de Grecs ${ }^{108}$ : Polyeidos ${ }^{109}$; Calchas $^{110}$; Pyrrhos ${ }^{111}$; Ménélas ${ }^{112}$; Ulysse ${ }^{113}$; Ajax fils d'Ö̈lée ${ }^{114}$; Mélampus ${ }^{115}$;

Apollodore, alors qu'Homère l'appelle Lampos (Waltz, p. 72 n. 1 et 2).

106 Sarpédon (277-282) (Bassetr, n 90) : “ Puis venait Sarpédon, le chef des Lyciens (...) un jeune et tendre duvet traçait à peine un sillon sur son menton brun ; sur sa tête, il avait un casque. Son corps était nu, mais à sa beauté se révélait la race de Zeus : car de ses deux yeux il lançait des traits de feu comme son noble père ». Sarpédon est un chef lycien qui combat aux côtés des Troyens.

107 Apollon est le fils de la Lycienne Léto, qualifié de Lykégénès dans Il., IV, 101.

108 La différence entre les proportions des groupes statuaires et celles des personnages s'explique par le fait que deux groupes statuaires associent un Grec et une Troyenne : Ménélas et Hélène ; Pyrrhos et Polyxène.

109 Polyeidos (40-44) (BAssett, nº 83 : appartenant au clan prophétique des Mélampodides, c'est un personnage popularisé par l'Énéide) : “ encore un autre devin, paré lui aussi du laurier de Phébus ». Il s'agit d'un devin et notable corinthien qui avait prédit à son fils Euchénor qu'il périrait devant Troie ; il a découvert le cadavre de Glaucos fils de Minos et l'a ressuscité ; il fut tué par Pâris (WaLtz, p. 63 n. 3). Une tradition locale de Mégare le fait séjourner dans cette cité, voisine de Corinthe.

110 Calchas (52-55) (Bassett, $\mathrm{n}^{\circ}$ 56). C'est un devin qui doit son pouvoir à Apollon et tient secrets les arrêts des dieux par crainte d'Agamemnon ; Christodoros suggère que cela venait peut-être de sa pitié pour l'armée des Grecs et fait peut-être allusion au sacrifice d’Iphigénie (Tissoni, p. 111). Calchas passe soit pour Mycénien soit pour Mégarien : dans ce dernier cas, la légende en fait le père de Calchédon, héros éponyme de Chalcédoine, cité située face à Byzance de l'autre côté du Bosphore et fondée elle aussi par Mégare (A. Roвu, Mégare, p. 226).

11 Pyrrhos (56-60) (BASSETt, $n^{\circ}$ 86) : “ le corps découvert; mais on le voyait lever les yeux comme s'il tendait son regard vers Ilion battue des vents ». C'est le fils d'Achille, plus souvent appelé Néoptolème (Pyrrhos signifie « le Roux »). Pour le groupe de Pyrrhos et Polyxène (192-208) (Bassett, nº 87), voir ci-dessus n. 102.

112 Ménélas et Hélène (165-170) (BASSETt, $n^{\circ} 74$ et 58). Il s'agit de la réconciliation d'Hélène et de Ménélas après la prise de Troie (Waltz, p. 68 n. 3).

113 Ulysse (171-175) (BASSETt, $\left.n^{\circ} 75\right)$.

114 Ajax fils d'Oïlée (209-214) (Bassett, n 29) : “ aucun duvet, de sa fleur, n’ombrageait le menton du héros. Son corps vigoureux était complètement nu (...) il brandissait l'aiguillon de la belliqueuse Ényo ». Ényo est la déesse de la guerre, la parèdre d'Arès ; elle pousse les guerriers au combat (WaLtz, p. 70 n. 3). Le personnage est décrit par Christodoros comme Ajax de Locres fils d'Oillée. Selon Tissoni, p. 173, il s'agirait plutôt du Grand Ajax, roi de Salamine et fils de Télamon, en raison de l'emploi d'épithètes s'appliquant à ce dernier (“ rempart puissant» d'après Homère, “au cœur vaillant » selon Quintus de Smyrne). Cependant, cette statue est certainement celle d'Ajax fils d'Ö̈lée, mais Christodoros a dû s'embrouiller dans son commentaire, bien que l'évocation de Locres soit correcte.

115 Mélampus (243-245) (BAssett, n 72 : devin ou, plus probablement, auteur de livres de 
Ajax fils de Télamon ${ }^{116}$; Achille ${ }^{117}$.

Seules quelques rares figures mythologiques paraissent échapper à la légende troyenne, mais l'on va voir qu'elles s'y rattachent en fait plus ou moins. L'unité de ce thème mythologique secondaire vient du fait qu'il se compose de légendes du Péloponnèse. Si l'on se souvient que Byzance a été fondée par des colons mégariens, certainement renforcés par des Péloponnésiens ${ }^{118}$, puis refondée comme Nouvelle Rome, on appréciera le lien subtil qui fut tissé entre le cycle péloponnésien et celui de Troie. Le premier cas est celui d'Amymone et Poséidon ${ }^{119}$. Amymone, fille de Danaos, fut surprise par un satyre près de la source de Lerne (en Argolide) puis délivrée par Poséidon, qui l'engrosse d'un fils, Nauplios, à l'origine de la cité de Nauplie ${ }^{120}$. Ce groupe constitue d'ailleurs la seule occasion où est représenté le dieu Poséidon, dont le rôle dans la mythologie troyenne est également fort important, on l'a vu.

Le deuxième cas concerne Héraclès et Augê ${ }^{121}$. Cette dernière est la fille d'Aléos roi de Tégée (en Arcadie), qui l'avait faite prêtresse vierge d'Athéna pour

divination $\mathrm{au} \mathrm{II}^{\mathrm{e}}$ siècle). Il semble qu'il faille en rester au devin évoqué dans l'Odyssée (Waltz, p. 71 n. 3 ; Tissoni, p. 187-188). Mélampus passait pour l'ancêtre de Polyeidos.

116 Ajax fils de Télamon (271-276) (BAssetr, n 30) : “ Il était nu (...) il n’avait pas encore son premier duvet (...) il liait ses cheveux avec un bandeau. Car il ne portait pas le casque et ne brandissait pas la lance ; il ne tenait pas sur son épaule son bouclier à sept peaux ; en lui se montrait cependant la hardiesse et le courage de son père Télamon ". Selon Waltz, p. 59, il est invraisemblable qu'Ajax fils de Télamon soit représenté sous les traits d'un adolescent imberbe, qui rappellerait plutôt le fils d'Oïlée (mentionné aux vers 209-214); Tissoni, p. 200, le croit également confondu avec Ajax fils d'Ö̈lée. Mais le premier portrait est aussi celui d'un adolescent imberbe, donc ce n'est pas un argument pour en faire celui du fils de Télamon ; l'armement décrit ici correspond bien à celui du fils de Télamon (un bouclier à sept peaux de bœuf recouvertes d'une plaque de bronze) alors que le fils d'Oïlée est armé d'une cuirasse de lin et d'un arc.

117 Achille (292-296) (Bassetr, n 26).

118 Mégare se trouve à la porte du Péloponnèse quand on vient du Nord. A. Roвu, Mégare, p. 282 : « La fondation de Byzance peut être considérée comme l'œuvre principale des Mégariens, mais ceux-ci furent aussi appuyés par des groupes de colons d'autre origine (argienne, béotienne, carystienne, voire même corinthienne) ».

119 Amymone et Poséidon (61-68) (Bassett, n 85).

120 WALTZ, p. 64 n. 1. L'évocation par Christodoros d'un mariage légitime entre Amymone et Poséidon relève d'une tradition marginale, représentée par Nonnos de Panopolis (Tissoni, p. 116).

121 Héraclès et Augê (136-143) (BAssett, n 61) : “ Héraclès montrait l’orbe de son menton imberbe, portant dans sa main qui tua le lion les pommes d'or, somptueux présent de la terre libyenne (...) Augê (...) elle laissait retomber son voile sur ses épaules, car ses cheveux n'avaient aucun bandeau pour les retenir ; elle levait et tendait ses mains comme si elle invoquait la fille de Zeus ». 
éviter un oracle prédisant qu’il serait tué par le fils de sa fille ; mais elle fut violée par Héraclès et en eut un fils, Télèphe, qui tua Aléos ${ }^{\mathbf{1 2 2}}$. Les deux statues voulaient probablement montrer Augê implorant Héraclès de l'aider à retrouver son fils Télèphe, qui lui fut enlevé à sa naissance ${ }^{123}$. Rappelons que le héros Héraclès est le fils de Zeus et de la mortelle Alcmène, et qu'“ Héraclès » est un nom mystique (signifiant “ la Gloire d'Héra »), qui lui fut imposé par Apollon au moment où il devint le serviteur d'Héra. On peut noter que la statue faisait allusion aux pommes d'or du jardin des Hespérides, le seul des douze travaux au cours duquel Héraclès voyage en Asie, ce qui est une première façon de le rattacher à la légende troyenne. Mais il faut surtout préciser que la première des grandes expéditions du jeune Héraclès le conduisit devant Troie. Il tua le monstre envoyé par Poséidon mais ne reçut pas sa récompense et menaça de revenir prendre la ville ; il le fit plus tard avec son compagnon Télamon ${ }^{124}$, et le seul fils du roi épargné par Héraclès fut Priam. En outre, selon une tradition, Augê vivait à la cour du roi de Troie, où elle fut aimée par Héraclès lorsqu'il vint prendre la ville, puis se rendit à la cour du roi de Mysie ; cependant, la version la plus courante situe le viol à Tégée et décrit Augê et Télèphe emmenés par des marchands d'esclaves en Mysie, où le roi épousa la mère et adopta le fils. Notons enfin que Télèphe a combattu les Grecs lors de leur première tentative contre Troie, que les fils de Télèphe émigrèrent en Étrurie après la prise de Troie, et que Roma est parfois considérée comme une fille de Télèphe, mariée à Énée.

Le troisième cas est celui d'Aglaos ${ }^{125}$. Christodoros affirme qu'il est le père de Polyeidos, alors que ce personnage s'appelait Coiranos ; rien ne permet de faire d'Aglaos un prophète ou un devin comme le dit Christodoros, certainement par confusion avec Polyeidos. La statue devait en fait représenter Aglaos fils de Thyeste. Atrée, frère jumeau de ce dernier et prétendant comme lui au trône de Mycènes, tua Aglaos et le donna à manger à Thyeste. Comme Atrée est le père d’Agamemnon et Ménélas, la légende se rattache aussi indirectement à l'épopée troyenne. Enfin, le dernier cas concerne Amphitryon ${ }^{126}$, fils d'Alcée, roi de Tirynthe, et de la fille de Pélops, Astydamie ; l'allusion de Christodoros au fait qu'il soit l'époux d'Alcmène autorise à lier cette statue à celle d'Héraclès, qui était

122 WALtZ, p. 67 n. 7

123 BASSETT, $\mathrm{n}^{\circ} 61$.

124 On notera que la statue d'Ajax fils de Télamon est décrite par Christodoros (vers 275276) avec des termes, hardiesse et courage, qui sont les qualités de Télamon lui-même (Waltz, p. 73 n. 4).

125 Aglaos (263-265) (BASSETt, n 28) : “ son front ceint d'un laurier au feuillage vigoureux ».

126 Amphitryon (367-371) (BAssett, $\left.n^{\circ} 35\right)$ : “ sa tête couronnée d’un laurier virginal (...) c'était en l'honneur de sa victoire sur les Taphiens que cette couronne parait la chevelure bouclée du belliqueux époux d'Alcmène ». 
le fils de Zeus et d'Alcmène, et dont on a vu l'importance dans la légende troyenne.

Si l'on se penche maintenant sur le thème apollinien, on peut d'abord avancer que son importance se mesure au nombre de devins et prêtres représentés : dans la plupart des cas, leur lien avec le dieu est explicitement affirmé. Il faut rappeler qu'Apollon est par excellence le dieu de la divination ou mantique ${ }^{127}$, illustrée en particulier dans ses sanctuaires de Delphes, Didymes et Claros. Parmi ces devins ou prêtres, le Troyen Chrysès et les Grecs Polyeidos, Calchas et Mélampus ont déjà été évoqués à propos de la légende troyenne. Il reste donc à considérer Palaiphatos ${ }^{128}$, Amphiaraos ${ }^{129}$ et Alcméon ${ }^{130}$. Notons que Palaiphatos et Alcméon sont en fait respectivement les fils d'une prophétesse et d'un devin (en l'occurrence Amphiaraos), ce qui montre bien que l'on a cherché à rattacher divers êtres mythiques à cette thématique oraculaire. La conception apollinienne de la collection s'apprécie aussi à l'aune des dix figures de poètes (ou de musiciens), qui se révèlent les plus nombreux parmi les auteurs d'œuvres de l'esprit ${ }^{131}$. Dans certains cas, Christodoros indique bien que leur art était inspiré par Apollon. On

127 Apollon (266-270) (BAssETt, n 42) : « Il roulait des regards divinateurs, comme s'il eût voulu, par ses oracles, délivrer les mortels de leurs maux »; Apollon (283-287) (BAssett, $\left.n^{\circ} 43\right)$ : « rend des oracles sur son trépied ».

128 Palaiphatos (36-37) (BAssETt, $\left.n^{\circ} 77\right)$ : « La chevelure couronnée de laurier ». Le personnage est connu comme poète épique athénien légendaire. Christodoros le qualifie de devin, ce qu'il a dû lire sur la base de la statue. Selon Waltz, p. 124, ce qualificatif provient peut-être d'une étymologie de son nom reposant sur l'expression homérique

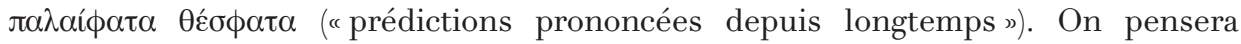
plus probablement avec Tissoni, p. 102-104 que ce qualificatif viendrait du fait que Palaiphatos était le fils de la prophétesse de Delphes Boio. On voit que l'on reste de toute façon dans l'univers apollinien.

129 Amphiaraos (259-262) (BASSETT, n 34) : « dans sa chevelure resplendissait une couronne de laurier ». Ce devin argien, prévoyant sa mort, ne participa qu'à son corps défendant à l'expédition des « Sept contre Thèbes » et périt en effet sous les murs de la ville (WALtz, p. 72 n. 3). Le personnage de ce devin est connu pour être protégé par Zeus et Apollon.

130 Alcméon (393-397). BassEtT, n 33, hésite entre Alcméon, fils d'Amphiaraos, personnage de la légende de Thèbes, et Alcméon de Crotone (vers 500 av. J.-C.), savant qui était un jeune contemporain de Pythagore. D'après la lecture de Christodoros, l'inscription portait sans doute “devin »: le poète la remet en question car sa tête n'est pas couronnée de laurier, et propose d'identifier la statue à celle d'Alcman, poète spartiate du VII ${ }^{\mathrm{e}}$ siècle. Mais l’inscription devait désigner le soi-disant “ devin » Alcméon, qui est le fils du devin bien attesté Amphiaraos et dont la vie fut gouvernée par plusieurs oracles. La confusion reflète en elle-même la conception apollinienne de la collection.

131 Apollon (266-270) (BAssetт, n 42) : « Le souverain maître du chant ». 
peut ainsi énumérer Hésiode ${ }^{132}$, Simonide ${ }^{133}$, Sappho ${ }^{134}$, Erinna ${ }^{135}$, Terpandre ${ }^{136}$, Stésichore $^{137}$, Homère ${ }^{138}$, Pindare ${ }^{139}$, Homère de Byzance ${ }^{140}$ et Virgile $^{141}$. Notons la valorisation du poète de Byzance Homère (III ${ }^{\mathrm{e}}$ siècle av. J.-C.) et le fait que sa statue se trouve à côté de celle de Virgile, l'Homère de Rome, comme l'a bien vu F. Tissoni ${ }^{142}$. Il n'est pas hasardeux qu'ait été ainsi sélectionné un poète nommé Homère, parmi les nombreux écrivains et savants qui s'illustrèrent à Byzance aux époques hellénistique et romaine : ce personnage fait bien sûr écho au grand Homère et à Virgile, principaux auteurs de la légende troyenne.

Parmi les “ intellectuels » représentés viennent ensuite, au nombre de huit,

132 Hésiode (38-40) (BASSEtT, $n^{\circ}$ 65) : “ semblait s'entretenir avec les Muses des montagnes ». Les Muses sont apparues à Hésiode sur l'Hélicon (WALtz, p. 63 n. 1).

133 Simonide (44-49) (BAssett, n 91 : poète ayant vécu en 556-468 av. J.-C.).

134 Sappho (69-71) (BAssetr, n 89 : présente dans la numismatique de Mytilène) : « L'abeille de Piérie aux chants mélodieux, la Lesbienne Sappho, était assise ».

135 Erinna (108-110) (BAssetr, $n^{\circ} 54$ : poétesse du IV siècle av. J.-C.) : « la vierge aux chants mélodieux (...) en silence elle distillait goutte à goutte le miel d'une abeille de Piérie ». La dernière expression s'applique à la composition de vers, comme dans le cas de Sappho (Waltz, p. 66 n. 1).

136 Terpandre (111-116) (BAssett, n 93 : vers 647 av. J.-C.). Terpandre de Lesbos aurait été appelé par les Spartiates pour mettre fin chez eux à une guerre civile (WALTZ, p. 66 n. 2). C'est l'oracle d'Apollon qui inspira aux Spartiates la décision de demander de l'aide à Terpandre, qui accorda les parties grâce à sa musique (Tissoni, p. 135-136).

137 Stésichore (125-130) (BAssett, n 92 : poète d'Himère en Sicile ayant vécu en 640-555 av. J.-C.) : “le poète aux chants mélodieux que jadis nourrit la terre des Sicules et qu'Apollon instruisit dans l'art de la lyre quand il était encore dans le sein de sa mère ». Stésichore passait pour le fils d'Hésiode, lui-même supposé descendre d'Apollon (WaLtz, p. 67 n. 1).

138 Homère (311-350) (BAssett, $\mathrm{n}^{\circ} 66$ ).

139 Pindare (382-387) (Bassett, n 81: 518-438 av. J.-C.) : “Pindare à la voix délicieuse, qu'Apollon à l'arc d'argent nourrit sur les hauteurs de l'Hélicon béotien et instruisit dans l'art des chants mélodieux ».

140 Homère de Byzance (407-413) (Bassetr, n 68 : fils de la poétesse Moirô). Homère de Byzance est aussi le fils d'Andromachos, personnage que la Souda qualifie de philologos. Cet Homère est un poète tragique et grammairien dont l'acmé se situe vers la $124^{\mathrm{e}}$ olympiade (284-281 av. J.-C.), qui a vécu à Athènes où il fut vraisemblablement vainqueur aux Dionysies, lors du concours de tragédies (M. DANA, "Byzance hellénistique et impériale : un centre culturel avant Constantinople? », in G. Tsetskhladze, S. Atasoy, A. Avram, Ş. Dönnez et J. Hargrave (éd.), The Bosporus: Gateway between the Ancient West and East (1st Millenium BC-5th Century AD), Oxford, 2013, p. 29-38, ici p. 32).

141 Virgile (414-416) (Bassett, n $\left.{ }^{\circ} 95\right)$.

142 Tissoni, p. 253. 
les philosophes et savants. On peut citer Aristote ${ }^{143}$, Anaximène ${ }^{144}$, Platon ${ }^{145}$, Pythagore $^{146}$, Démocrite ${ }^{147}$, Apulée ${ }^{148}$, Phérécide ${ }^{149}$ et Héraclite ${ }^{150}$. On dénombre ensuite trois groupes de trois personnages. Il s'agit d'abord des auteurs de théâtre Euripide $^{151}$, Cratinos ${ }^{152}$ et Ménandre ${ }^{153}$ : on remarquera que le premier et le troisième étaient les auteurs les plus connus à l'époque impériale, respectivement pour la tragédie et la comédie ; de plus, les statues des deux auteurs de comédies, Cratinos et Ménandre, se trouvaient côte à côte. On trouve ensuite trois historiens, dont les statues sont regroupées, hormis le fait que Pindare était placé entre les deux derniers : Thucydide ${ }^{154}$, Hérodote ${ }^{155}$ et Xénophon ${ }^{156}$. On dénombre enfin trois orateurs : Eschine ${ }^{157}$, Démosthène ${ }^{158}$ et Isocrate ${ }^{159}$. Il faut aussi citer un

143 Aristote (17-22) (Bassett, n 45 : sa statue était probablement proche de celle de Démosthène par la position des mains) : “il était debout, les mains jointes et entrelacées ».

144 Anaximène (50-51) (BAssett, $\left.n^{\circ} 36\right)$.

145 Platon (97-98) (Bassett, $\left.n^{\circ} 82\right)$.

146 Pythagore (120-124) (BAssett, $n^{\circ} 88$ ).

147 Démocrite (131-135) (Bassett, n $\left.{ }^{\circ} 52\right)$.

148 Apulée (303-305) (BAssett, $\left.n^{\circ} 44\right)$ : “ lui qu’une Sirène ausonienne avait initié à sa science que nul ne doit divulguer ». Selon WALTz, p. 74 n. 5, Christodoros ferait allusion à une magicienne italienne qui l'aurait instruite dans son art : elle aurait joué à l'égard d'Apulée le rôle des magiciennes thessaliennes vis-à-vis de Lucius, car l'Âne d'or était vu comme une autobiographie. Tissons, p. 210, objecte à cette hypothèse que l'initiation d'Apulée a eu lieu en Grèce : la sirène est associée à la magie et elle est qualifiée d'ausonienne simplement car Apulée est latin.

149 Phérécide (351-353) (Bassett, n 80 : vi ${ }^{\mathrm{e}}$ siècle) : “Phérécide de Syros (...) tenant en main l'aiguillon divin de la science ». D'après WALtz, p $76 \mathrm{n}$. 5, le poète fait allusion au compas de l'astronome ou à un autre instrument de travail. Pour Tissoni, p. 226228, il ne doit pas s'agir d'un réel instrument de travail, car Christodoros imite ici étroitement Nonnos et emploie un symbole ; de plus, Phérécide est surtout connu comme philosophe et pas nécessairement comme astronome.

150 Héraclite (354-356) (BAssett, n 60 : Héraclite d'Éphèse ayant vécu en 535-475 av. J.-C.).

151 Euripide (32-35) (BASSETt, $\left.n^{\circ} 55\right)$.

152 Cratinos (357-360) (Bassett, n ${ }^{\circ}$ 71). C'est un poète de comédie du ve siècle av. J.-C., qui attaqua les hommes d'État (WaLtz, p. 76 n. 6).

153 Ménandre (361-366) (Bassett, n 73 : 342/341-293/289 av. J.-C.).

154 Thucydide (372-376) (BAssEtT, $\left.n^{\circ} 94\right)$ : “ il tenait la main droite levée ».

155 Hérodote (377-381) (BAssett, $\left.n^{\circ} 64\right)$.

156 Xénophon (388-392) (Bassett, n 97).

157 Eschine (13-16) (BAssett, $\left.n^{\circ} 31\right)$.

158 Démosthène (23-31) (Bassett, $n^{\circ} 53$ ).

159 Isocrate (256-258) (BASSETt, n 69 : 436-338 av. J.-C.). 
athlète sur l'identité duquel Christodoros hésite entre trois personnages ${ }^{160}$ et en qui F. Tissoni a certainement raison de voir le lutteur Milon de Crotone ${ }^{161}$.

Terminons par un groupe de cinq hommes d'État. Trois sont Grecs : Alcibiade ${ }^{162}$, Périclès ${ }^{163}$ et Charidèmos ${ }^{164}$. Deux sont Romains : Jules César ${ }^{165}$ et Pompée ${ }^{166}$. La statue de César reprend essentiellement l'iconographie de Jupiter combattant ${ }^{167}$ : il faut rappeler que César, en prenant le prénom d'imperator, était le triomphateur par excellence, l'incarnation de Jupiter pendant la cérémonie du triomphe ${ }^{168}$; il s'agit là d'un élément fondateur du pouvoir impérial romain. On peut ajouter que la statue de César semble aussi s'inspirer d'un geste d'une sculpture de Diane, déesse dont nous avons vu qu'elle jouait, avec son frère Apollon, un rôle d'intermédiaire entre Jupiter et les Romains. Le second homme d'État romain est Pompée. Il forme a priori un couple évident avec César, dont il fut le rival

160 Philon, Philammon ou Milon (228-240) (Bassett, $n^{\circ}$ 96) : “ athlète expert dans l'art de la lutte (...) sa barbe était longue et touffue; ses traits lançaient, comme des javelots, une terreur guerrière (...) ses mains étaient jointes et ses deux bras puissants se contractaient ». L'hésitation concerne Philon de Corcyre, Philammon d'Athènes et Milon de Crotone (Waltz, p. 71 n. 1).

161 Tissoni, p. 182 : en effet, Philon et Philammon sont exclusivement connus comme pugilistes.

162 Alcibiade (82-85) (Bassett, $\mathrm{n}^{\circ}$ 32).

163 Périclès (117-120) (Bassett, $\left.n^{\circ} 79\right)$.

164 Charidèmos (241-242) (omis par BAssetT) : " général athénien qui maintint sous son autorité l'armée ». D'après WALTZ, p. 125, au Ive siècle les mercenaires de Charidèmos s'étaient fait remarquer par leurs déprédations, mais c'est Charès et non Charidèmos qui se vit ensuite confier cette armée. Pour Tissoni, p. 187, cette hypothèse au sujet de Charès n'est pas convaincante et mieux vaut en rester à Charidèmos. Charès est le stratège athénien envoyé au secours des Byzantins assiégés par Philippe de Macédoine.

165 Jules César (92-96) (Bassett, $n^{\circ}$ 48).

166 Pompée (398-406) : “ Pompée, le chef des Ausoniens (...) il tenait - monument éclatant de la valeur qui extermina les Isauriens - foulé sous ses pieds, les glaives d'Isaurie (...) C'était là ce héros, l'honneur de sa patrie, de qui est issu l'illustre famille d'Anastase ». Sur la foi ce passage, Bassett, $n^{\circ}$ 84, identifie cette statue à celle d'un Pompeius qu'elle

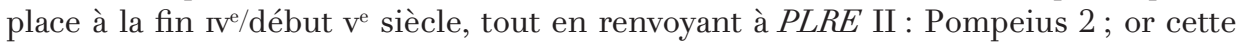
dernière notice s'applique à un neveu d'Anastase, dont la carrière est postérieure à la victoire sur les Isauriens de 498. Cette statue ne peut être que celle du grand Pompée, dont Anastase revendiquait l'ascendance, ce qui a dû jouer dans le nom de l'un de ses neveux. Il est manifeste que Christodoros, poète de la cour d'Anastase, interprète une statue antique en fonction de son temps : Pompée avait en particulier vaincu les pirates du Sud de l'Asie Mineure.

167 Voir note 77.

168 Ch. Meier, César, trad. J. Feisthauer, Paris, 1989, p. 442. 
dans les guerres civiles. Mais il faut ajouter que les deux hommes se trouvaient aussi en compétition dans le culte d'Aphrodite, vénérée sous la forme de Vénus Genitrix par César et Vénus Victrix par Pompée ${ }^{169}$. Or cette déesse, on le sait, était particulièrement à l'honneur dans la collection.

\section{Les cultes païens de Byzance}

Pour interpréter cette collection, il importe de la situer dans son contexte historique. Il est manifeste que la légende troyenne répondait à la fondation d'une Nouvelle Rome. Constantinople prétendait par ailleurs recueillir l'héritage de la paideia grecque, symbolisée par de nombreux personnages illustres. Ce sont finalement les représentations des divinités, et en particulier la thématique apollinienne, qui appellent des commentaires plus précis. Il faut ici revenir à l'édifice lui-même et à sa dénomination de “ Zeuxippe ». Nous avons vu que les bains fondés par Constantin se trouvèrent installés sur un lieu de culte solaire apollinien. Ce fut déjà un puissant motif pour créer une collection à ce point inspirée par le dieu Apollon, dont la fonction solaire est nettement affirmée par Christodoros ${ }^{170}$ et devait donc être notoire.

Au-delà de cette figure centrale, il importe de s'interroger sur les divinités honorées dans la Byzance antérieure à Constantin. G. Dagron ${ }^{171}$ a établi une liste exhaustive de nombreux cultes, connus essentiellement par Denys de Byzance ( $\mathrm{I}^{\mathrm{e}}$ siècle) et Hésychios de Milet $\left(\mathrm{vI}^{\mathrm{e}} \text { siècle }\right)^{172}$. Mais les renseignements les plus intéressants sur la question proviennent de Malalas. Le chroniqueur écrit :

“ En cette même année [324] ce même empereur Constantin ordonna que les trois temples d'Hélios, d'Artémis la lune et d'Aphrodite, situés à Constantinople sur ce qui était appelé auparavant l'Acropole, subsistent dorénavant sans revenus „173.

Il mentionne à nouveau précisément ces trois temples pour affirmer que Théodose $\mathrm{I}^{\mathrm{er}}$ (379-395) les convertit à des usages profanes ${ }^{174}$. Ces temples

169 Meier, César, p. 430.

170 Apollon (72-77) (Bassetr, n 41) : « car c'est le soleil que ce dieu Phébus ».

171 Dagron, Naissance, p. 367-371.

172 Les deux auteurs ne se situent pas sur le même plan : Denys livre une description du Bosphore rédigée au temps de l'empire païen, Hésychios mentionne des légendes réinterprétées à l'époque chrétienne.

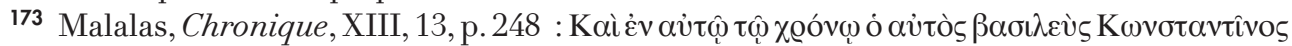

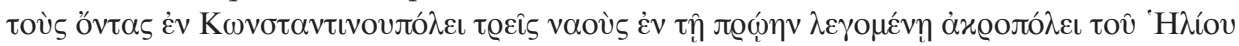

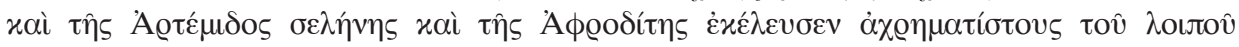

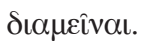

174 Malalas, Chronique, XIII, 38, p. 267. Selon les interprétations de C. Mango, Le 
sont évoqués par d'autres auteurs du vi ${ }^{\mathrm{e}}$ siècle. Évagre parle de “ la région septentrionale, là où sont les arsenaux de la ville, depuis ce qu'on appelle le

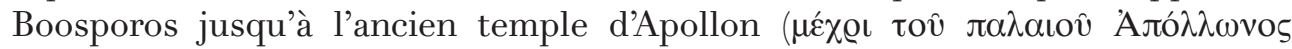
iع@ov̂) „ ${ }^{175}$. Il est évident qu'une équivalence peut être ainsi posée entre le temple d'Hélios et celui d'Apollon, conformément à leur assimilation sur les lieux mêmes des bains de Zeuxippe. Zosime évoque, quant à lui, le temple d'Aphrodite situé au nord-est de l'Acropole ${ }^{176}$, elle-même localisée à la pointe de la presqu'île. Un autre temple, dédié à Poséidon, est mentionné par Hésychios de Milet : installé, comme il se doit, le plus près de la mer, il était proche des temples d'Aphrodite et d'Artémis ${ }^{177}$ - ce qui confirme l'emplacement de ces derniers sur l'Acropole. D'après la description topographique d'Hésychios, il semble même que le temple d'Apollon-Hélios devait se trouver le plus à l'intérieur de la presqu'île, ce qui nous rapproche du site des bains de Zeuxippe.

Ces indications des auteurs du vi ${ }^{\mathrm{e}}$ siècle sont presque toutes déjà fournies par des textes plus anciens, évocateurs des traditions religieuses de Byzance. Au $\mathrm{II}^{\mathrm{e}}$ siècle, Denys de Byzance évoque un bois sacré et un sanctuaire d'Apollon situés après le Boukolon (partie méridionale de la presqu'île) ${ }^{178}$. Ce temple d'Apollon est significativement le seul édifice sacré mentionné par une inscription de Byzance. Elle se compose de deux décrets civiques datés de 175-171 av. J.-C. et prévoyant

développement urbain de Constantinople (IV $V^{\mathrm{e}}-V I I^{\mathrm{e}}$ siècles), Paris, 1990, p. 33, le temple d'Hélios est “ transformé en maison de rapport appartenant à Sainte-Sophie, celui d'Artémis en taverne, celui d'Aphrodite en écurie où étaient gardés les chariots du Préfet du Prétoire ».

175 Évagre le Scholastique, Histoire ecclésiastique, II, 13, éd. J. Bidez et L. Parmentier, trad. A.-J. Festugière, B. Grillet et G. Sabbah, Tome I (livres I-III), Paris, 2011, p. 300-301.

176 Zos., II, 30, 3 [Zosime, Histoire nouvelle, Tome I (livres I et II), éd. et trad. F. Paschoud,

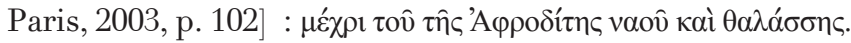

177 Hsch.Mil., 13-14 [Accounts of Medieval Constantinople. The Patria, éd. Th. Preger, trad.

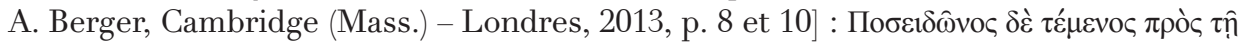

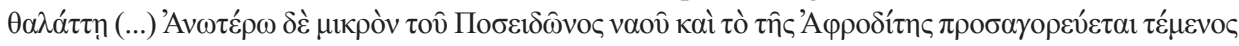

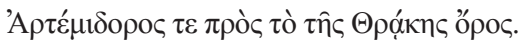

178 Dion.Byz., 26 [Dionysii Byzantii Anaplus Bospori, éd. R. Güngerich, Berlin, 1958, p. 13] :

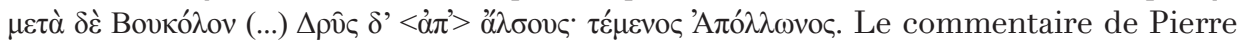
Gilles, p. 66, est intéressant : “ Apollon eut bien six temples auprès du Bosphore (...), deux à Byzance dont l'un au Xèrolophos avec un trépied très ancien et l'autre avec un bois sacré de laurier près d'une extrémité de la Corne d'Or ». Le Xèrolophos se situe à l'extrême sud-ouest de la zone enserrée par la muraille de Constantin. C'est le second temple qui nous intéresse ici. Il faut noter que le lieu-dit $\Delta \rho \hat{\iota} \varsigma$ désigne « l'arbre », ce qui s'applique bien au bois sacré, dont Gilles est fondé à penser qu'il se composait de lauriers. 


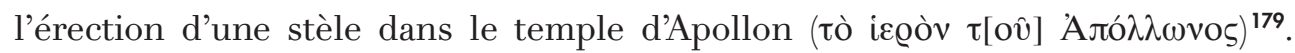
Denys de Byzance mentionne aussi un temple antique de Poséidon, au-dessus duquel se trouvent les lieux voués aux jeux par la cité ${ }^{180}$. À propos du sanctuaire d'Artémis, sur lequel nous disposons de peu de données, Hérodote évoque quand même un autel d'Artémis Orthôsia situé dans l'antique Byzance ${ }^{181}$.

Parmi les quatre dieux honorés sur l'Acropole de Byzance, la numismatique souligne la place singulière d'Apollon et de Poséidon. Apollon est représenté par trois séries de monnaies, où il figure au droit avec les cheveux longs et la couronne de lauriers, et où le revers comporte toujours une allusion au sanctuaire de Delphes ${ }^{182}$. Dans la première, le revers comprend un bœuf et un dauphin, qui rappellent sa fonction d'Apollon bouvier et le nom même de Delphes ${ }^{183}$. Dans la deuxième, le revers comporte l'omphalos delphique surmonté d'une sorte d'obélisque, ce

179 A. ŁaJTAR, Die Inschriften von Byzantion. I, Bonn, 2000, p. 20, 1. 63-64. Il s'agit d'honorer Eudamos de Séleucie, qui était conseiller du roi séleucide Antiochos IV et dont la cité de Byzance fait son proxène.

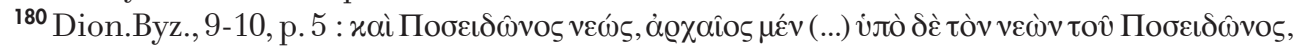

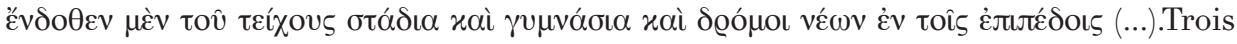
commentaires de Pierre Gilles sont là encore dignes d'intérêt [les passages en italiques qui suivent constituent des traductions du texte de Denys de Byzance] : « la citadelle de Byzance, là où fut, selon Denys, un temple de Poséidon, antique » (p. 67); “ Au-delà aussi, dit-il, du promontoire Bosporios, il y a un temple de Poséidon antique (...)Audessous du temple de Poséidon, à l'intérieur du rempart de la ville, il y avait des stades et des gymnases » (p. 103) ; “Puis Denys ajoute qu'il y avait au-delà du promontoire Bosporios un temple de Poséidon, antique [...], et qu'au-dessus du temple de Poséidon [...], il y avait des stades, des gymnases, des pistes de course pour les jeunes gens sur les replats, qu'après la pointe du promontoire Bosporios, la Corne d'Or faisait place à trois ports défendus par des tours et des môles » (p. 310). Dans la deuxième citation, dont la topographie est en contradiction avec celle de la troisième, manifestement exacte, Mango, Le développement urbain, p. 18 n. 29, propose de corriger le début du passage en lisant : “ au-dessus du temple».

181 Hdt., IV, 87 : « [Darius] contempla aussi le Bosphore, et il fit dresser sur le rivage deux stèles de marbre blanc où figurait, en caractères assyriens sur l'une et grecs sur l'autre, la liste des peuples qui le suivaient (...) Les Byzantins transportèrent plus tard les deux stèles dans leur ville et s'en servirent pour édifier l'autel d'Artémis Orthôsia, moins une pierre qu'ils laissèrent près du temple de Dionysos à Byzance, et qui est couverte de caractères assyriens » (trad. A. Barguet).

${ }^{182}$ La chevelure est reprise par l'iconographie des statues des bains de Zeuxippe et les lauriers font écho au bois sacré tout proche. Quant au thème delphique et donc oraculaire, nous avons vu à quel point il est également décliné par la statuaire.

183 E. Schönert-Geiss, Die Münzprägung von Byzantion. Teil I: Autonome Zeit, Berlin Amsterdam, 1970, p. 131, n 951-953 : série au bœuf (cuivre des $\mathrm{v}^{\mathrm{e}}-\mathrm{IV}^{\mathrm{e}}$ siècles). 
qui doit renvoyer au culte d'Apollon Karinos ou Agyieus (“protecteur des rues ») propre à Mégare, métropole de Byzance ${ }^{184}$. Dans la troisième, le revers inclut un trépied delphique ${ }^{185}$. En ce qui concerne Poséidon, deux séries le représentent aux revers de monnaies figurant au droit Déméter ${ }^{186}$ et Dionysos ${ }^{187}$. Mais il est aussi lui-même employé au droit. Dans ce cas, une première série comporte un revers au trident et au dauphin ${ }^{188}$, animal qui figure sur le groupe statuaire de Poséidon et Amymone ; dans une seconde série, le revers inclut une proue de navire avec un éperon ${ }^{189}$, une allusion à la puissance maritime de Byzance.

En dehors des quatre grands dieux évoqués (Apollon, Artémis, Aphrodite et Poséidon), quelques héros représentés dans les bains de Zeuxippe étaient également honorés dans l'antique Byzance. Selon Hésychios (vi ${ }^{\mathrm{e}}$ siècle), au nord de l'Acropole se trouvaient des autels dédiés à Ajax et Achille, et à cet endroit étaient justement installés les bains d'Achille ${ }^{190}$. L'existence de ces thermes dits d'Achille est confirmée par une loi de Théodose II (datée vers 440) ${ }^{191}$ : le parallélisme avec l'étymologie des bains de Zeuxippe oriente sûrement, là aussi, vers un culte local d'Achille. En ce qui concerne Ajax, le témoignage de Denys de Byzance (II ${ }^{\mathrm{e}}$ siècle) place un lieu-dit d'après son nom au nord de la Corne d'Or, mais ne l'associe pas à un sanctuaire, si bien que ce dernier pouvait effectivement se trouver près de l'autel d'Achille. Il reste que Denys apporte des renseignements intéressants sur Ajax : il s'agit du fils de Télamon, particulièrement honoré par Mégare, métropole de Byzance ${ }^{192}$. Un dernier héros présent au Zeuxippe était

${ }^{184}$ Idem, p. 144-145, n 1215-1232 : série à l'obélisque (cuivre du III ${ }^{\mathrm{e}}$ siècle). Pour Apollon Karinos honoré à Mégare : Paus., I, 44, 2.

185 Ibidem, p. 145-146, n 1233-1243 : série au trépied (cuivre du III $^{\mathrm{e}}$ siècle).

186 Ibidem, p. 133-137, n 979-1042 : argent (d'étalon phénicien) (milieu du iII ${ }^{\mathrm{e}}$ siècle-vers 220/219); droit : tête de Déméter / revers : Poséidon assis avec son trident et une poupe de navire.

${ }^{187}$ Ibidem, p. 139-140, n 1103-1130 : série au Dionysos / Poséidon (cuivre du III ${ }^{\mathrm{e}}$ siècle) ; droit : tête de Dionysos / revers : Poséidon debout avec son trident et une Nikè.

188 Ibidem, p. 137-139, n 1044-1102 : série au Poséidon et au trident (cuivre du III ${ }^{\mathrm{e}}$ siècle).

189 Ibidem, p. 146, n 1244-1250 : série au Poséidon et à la proue (cuivre du III siècle) ; droit : tête de Poséidon avec un trident derrière / revers : proue de navire avec éperon.

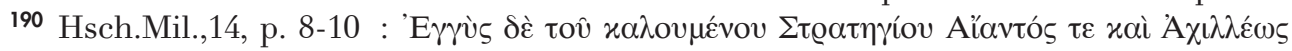

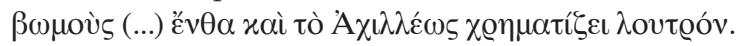

191 Code Justinien, XI, 43, 6, 2-3. Pierre Gilles, p. 375-376, cite cette loi.

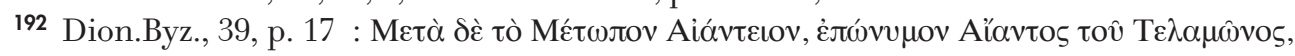

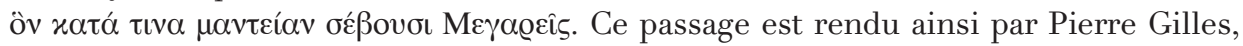
p. 128 : “ Mais je reviens à Denys qui, du Métôpon continue ainsi sa Navigation. Après le Métôpon, dit-il, il y a Aianteion qui a tiré son nom d'Ajax, fils de Télamon, que selon quelque oracle honorent les Mégariens ». 
vénéré à Byzance, en la personne d'Amphiaraos : Denys situe son sanctuaire à Sykai (autrement dit Galata), au nord de la Corne d'Or ${ }^{193}$. Il faut noter que ce faubourg de Sykai regroupait les cultes des deux déesses connues au Zeuxippe, Artémis et Aphrodite ${ }^{194}$ : cela montre que l'association de ces divinités était familière aux yeux des habitants de Byzance.

La statuaire des bains de Zeuxippe met donc l'accent sur des cultes bien précis. Parmi les figures des légendes péloponnésiennes, elle renvoie d'abord à des divinités vénérées à Mégare, métropole de Byzance : on a pu ainsi évoquer Apollon, Ajax et Amphiaraos. Les deux premiers sont honorés sur l'Acropole ou à ses abords. C'est là que se trouvaient les sanctuaires les plus vénérables : ceux d'Apollon et de Poséidon sont respectivement qualifiés de palaios et archaios par Évagre et Denys de Byzance. Ils étaient accompagnés par ceux d'Artémis et Aphrodite, deux déesses par ailleurs adorées ensemble dans le faubourg de Sykai. Il s'avère donc que les bains de Zeuxippe honorent avant tout les grands dieux de l'Acropole de Byzance. C'est surtout le cas d'Apollon, qui était vénéré à l'emplacement même des thermes : sa mythologie envahissait littéralement leur décor. La numismatique montre qu'Apollon et Poséidon étaient bien les deux principaux dieux civiques, et en particulier Apollon, dont le sanctuaire recueillait les stèles honorifiques érigées par la cité.

Or la légende des origines de Byzance met exactement en scène ces deux dieux. Le héros fondateur Byzas a, de manière tout à fait classique, agi sur l'injonction de l'oracle de Delphes. De façon plus originale, Byzas était le fils de Poséidon et il a fortifié Byzance avec l'aide d'Apollon et de Poséidon. On n'a pas assez remarqué que cette légende est un doublet exact de la fondation des murailles de Troie, on l'a vu, par ces deux mêmes dieux ${ }^{195}$. En outre, les trois dieux honorés sur l'Acropole elle-même, Apollon, Artémis et Aphrodite, sont les trois principales divinités

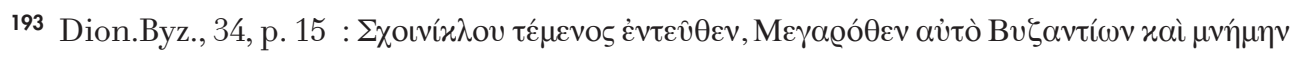

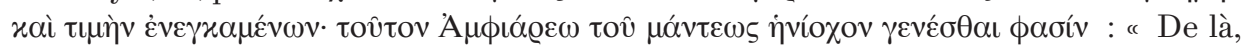
un sanctuaire de Schoiniklos. Les Byzantins venus de Mégare le commémorèrent et honorèrent ; on dit qu'il devint le cocher du devin Amphiaraos » (trad. J.-P. Grélois, dans Pierre Gilles, p. 123 n. 643). Hsch.Mil., 14, p. 10, confirme que ce sanctuaire était

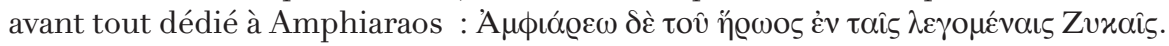

194 Dion.Byz., 36, p. 16. Là encore, le commentaire de Pierre Gilles, p. 451, est instructif : “ à l'intérieur des Sykai se trouvèrent inclus le temple d'Amphiaraos et celui d'Artémis Phôsphoros [qui apporte la lumière] et Aphrodite Praeia [douce, bienveillante] ». Il existe des parentés entre l'Artémis Phôsphoros de Byzance et l'Artémis Sôteira de Mégare (M. Dana, Culture et mobilité dans le Pont-Euxin. Approche régionale de la vie culturelle des cités grecques, Bordeaux, 2011, p. 112).

195 A. Rовu, Mégare, p. 287 (Apollon participa aussi à la construction des murs de Mégare, métropole de Byzance). 
favorables aux Troyens ${ }^{196}$. Autrement dit, la cité de Byzance avait développé une mythologie très proche de celle de sa voisine asiatique, Troie. On ne dira pas que Byzance fut pour cette raison choisie comme Nouvelle Rome par Constantin, car les considérations stratégiques ont dû primer. Mais il est évident que Constantin exploita à fond cette parenté mythologique préexistante, et d'abord en faisant décorer les bains de Zeuxippe.

\section{Constantin et la décoration de Constantinople}

Afin de comprendre les principes qui ont guidé Constantin ou ses conseillers, il faut aussi replacer la collection du Zeuxippe dans le cadre de la décoration de Constantinople à la même époque. On peut indiquer d'abord que le bâtiment du Sénat présent sur le forum de Constantin fut orné de la porte de bronze du temple d'Artémis à Éphèse, et que sur cette porte étaient, entre autres, représentés Poséidon et Apollon ${ }^{197}$ : on retrouve ainsi trois des quatre grands dieux évoqués. Plus significatif est le fait que, sur le même forum de Constantin, fut installé un groupe statuaire en bronze représentant Pâris offrant à Aphrodite la pomme d'or de la discorde ${ }^{198}$, geste à l'origine de la guerre de Troie. Surtout, dans la base de la colonne surmontée de la statue impériale, au centre de ce même forum, Constantin semble bien avoir installé le Palladion. Cette statue archaïque de Pallas ou Athéna aurait été saisie à Troie puis placée à Rome, d'où Constantin la fit venir : elle était censée rendre imprenable la ville qui la possédait ${ }^{199}$. Il est donc manifeste que

196 De plus, Achille et Ajax, deux grands héros grecs de la guerre de Troie, étaient honorés à proximité.

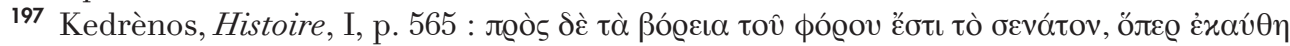

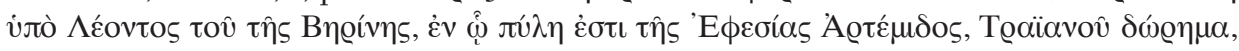

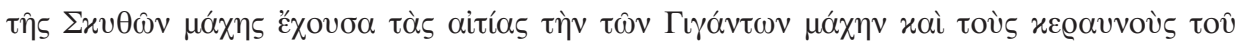

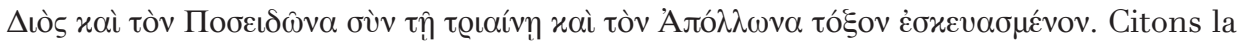
transcription de ce passage par Pierre Gilles, p. 148 : [l’incendie qui éclata sous le règne de Léon $\mathrm{I}^{\mathrm{er}}$ “ détruisit entièrement, racontent Zônaras et Kedrènos, dans la partie nord du forum [...] de Constantin, le très grand bâtiment [...] appelé sénat, orné de statues de bronze et de dalles de porphyre. Il y avait là la porte de l'Artémis d'Éphèse, un don de Trajan [...] tiré du butin des Scythes [...], avec [...] le combat des Géants, les foudres de Zeus, Poséidon avec le trident, Apollon avec [...] des flèches ».

198 Chôniatès, Histoire, p. 648, 1. 42 -43 [Nicetae Choniatae Historia, éd. J. Van Dieten, Berlin

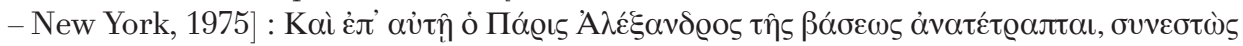

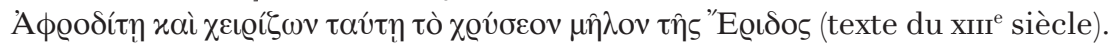

199 Malalas, Chronique, XIII, 7, p. 246 : " Ce même Constantin importa en secret de Rome une statue de bois appelée Palladion et il la plaça sur le forum qu'il avait bâti, dans le soubassement de la colonne supportant sa statue ; certains habitants de Byzance 
la thématique troyenne a inspiré Constantin de façon globale. Ajoutons que sa propre statue sur la colonne de son forum était un remploi d'une statue de bronze enlevée à Troie 200 : ce fait ne saurait relever du hasard, alors que l'empereur avait l'embarras du choix pour se saisir de statues antiques. On ne peut enfin oublier que Constantin a probablement d'abord songé à établir sa nouvelle capitale sur le site de Troie elle-même. Cette possibilité a souvent été évoquée comme une pure fiction, uniquement destinée à asseoir la légitimité romaine de Constantinople. Mais deux auteurs, le chrétien Sozomène ( $\mathrm{v}^{\mathrm{e}}$ siècle) et le païen Zosime ( $\mathrm{vI}^{\mathrm{e}}$ siècle), laissent entendre que les travaux avaient commencé : même s’ils donnent du changement d'avis de Constantin des versions différentes, l'accord sur ce point de deux auteurs que tout oppose par ailleurs donne une crédibilité certaine à cette tentative troyenne ${ }^{201}$.

affirment qu'elle se trouve là » (trad. Cheynet, Byzance, p. 176). Procop., Goth., I, 15, 9-14 [Procope, Histoire des Goths, trad. D. Roques, Paris, 2015, p. 74] : « Selon la tradition Diomède avait partagé à Bénévent la compagnie d'Énée fils d'Anchise, quand celui-ci était venu d'Ilion et il avait donné à la cité une statue d'Athéna, conformément à la volonté de l'oracle ; c'était la statue qu'avec Ulysse il avait dérobée lorsque tous deux étaient allés en espions à Ilion, avant la prise de celle-ci par les Grecs (...) De leur côté, les Byzantins affirment que cette statue s'est vue déposée et enfouie par l'Empereur Constantin sous le forum qui porte son nom ».

200 Malalas, Chronique, XIII, 7, p. 245-246 : “ il bâtit aussi un grand et très beau forum au milieu duquel il érigea une colonne admirable toute de porphyre et, à son sommet, une statue de lui-même, ornée de sept rayons sur la tête, œuvre de bronze qu'il avait apportée alors qu'elle se trouvait à Ilion, ville de Phrygie [sic] » (trad. Cheynet, Byzance,

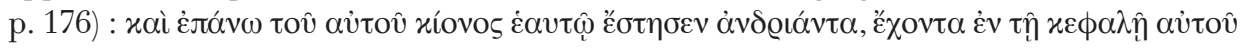

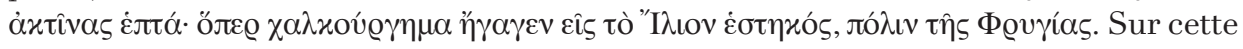
statue de Constantin, voir en dernier lieu J. Bardill, Constantine, Divine Emperor of the Christian Golden Age, Cambridge, 2012, p. 28-125 (chapitre 2 : “ Emperors and Divine Protectors »). Disons simplement que cette statue radiée comporte un aspect solaire qui a été selon toute probabilité incorporé dans une légitimation chrétienne du pouvoir, fondée sur la lumière du Christ. Toute une littérature ancienne et moderne en a fait une statue apollinienne, alors que Constantin ne pouvait accepter à cette époque que sa personne fût directement associée à un dieu païen.

201 Sozomène, Histoire ecclésiastique, II, 3, 2-3, éd. J. Bidez, trad. A.-J. Festugière, Paris, 1983, p. 236-239 : “ S'étant rendu à la plaine devant Ilion près de l'Hellespont, au-delà de la tombe d'Ajax, là où les Achéens jadis en guerre contre Troie eurent, dit-on, leur mouillage et leurs baraquements, il traça le plan de la ville, telle et aussi grande qu'elle devait être ; et il fit bâtir des portes fortifiées sur une éminence, qui se laissent voir aujourd'hui encore depuis la mer à ceux qui naviguent au long de la côte. Tandis qu'il était occupé à cet ouvrage, Dieu la nuit lui apparut et lui rendit oracle de chercher un

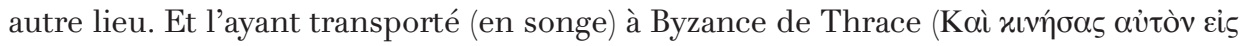


En lien étroit avec la revendication des origines troyennes, le décor constantinien de la nouvelle capitale exalta la figure centrale d'Apollon. La description la plus éloquente est fournie par l'évêque Eusèbe de Césarée, conseiller de l'empereur :


s'était glorifiée si longtemps, étaient exposés aux yeux de tous, sur toutes les places publiques de la ville impériale, de sorte qu'était offert à la vue le spectacle honteux, ici d'Apollon Pythien, là d'Apollon Sminthien, à l'hippodrome même des trépieds de Delphes, au palais des Muses de l'Hélicon. Toute la ville qui porte le nom de l'empereur fut totalement remplie d'objets consacrés, des chefs-d'œuvre artistiquement ouvragés en bronze provenant des diverses provinces : après leur avoir en vain offert en sacrifices sous le nom de dieux, pendant de longs siècles, d'innombrables hécatombes et holocaustes, ceux qui étaient malades de l'erreur apprirent enfin sur le tard à penser sainement, lorsque l'empereur en fit des jouets d'amusement et de dérision pour les spectateurs » 202 .

Notons que, si le texte d'Eusèbe s'apparente à une hagiographie chrétienne, il ne peut pour autant dissimuler le soin apporté à l'ornement de la ville au moyen de statues apolliniennes. La relation avec la légende troyenne est opérée par la représentation d'Apollon Sminthien ou Smintheus : cette épithète signifie le “ destructeur de rats » et une telle figure d'Apollon est avant tout honorée en Troade 203 ; en outre, dans l'Iliade, Apollon est apostrophé comme “ seigneur de Ténédos, Sminthée ! „204. Au palais impérial furent figurées les Muses de l'Hélicon ${ }^{205}$, qui constituent un saisissant écho à la statue d'Hésiode du Zeuxippe.

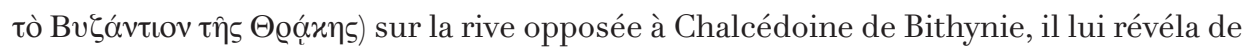
fonder là sa ville et de lui donner son nom de Constantin ». Zos., II, 30, 1, p. 102-103 : " s'étant trouvé entre le cap Sigée de Troade et l'ancienne Ilion, il découvrit un endroit qui se prêtait à la construction d'une ville, y jeta des fondations et éleva une portion de muraille jusqu'à une certaine hauteur, que ceux qui naviguent vers l'Hellespont peuvent voir encore aujourd'hui ; mais il vint à changer d'idée, abandonna cette entreprise inachevée et se rendit à Byzance ». Selon F. PAschoud, in Zosime, Histoire nouvelle, p. 241, la chronologie prouverait que des travaux ne purent être entrepris du côté de Troie ; mais cet argument n'est guère convaincant car la victoire de Chrysopolis contre Licinius a eu lieu le 18 septembre 324, et le début des travaux à Constantinople, coïncidant avec la nomination de Constance II comme césar, le 8 novembre 324 : cet intervalle de un mois et demi a pu laisser le temps de bâtir des fondations, une portion de muraille ou des portes.

202 Eusèbe de Césarée, Vie de Constantin, III, 54, 2-3, éd. F. Winkelmann, trad. M.-J. Rondeau, comm. L. Pietri, Paris, 2013, p. 422-423.

203 BASSETt, p. 245-246.

204 Il., I, 29.

205 BAssett, p. 150-151. 
Mais c'est l'Apollon Pythien, celui de Delphes, qui paraît avoir été surtout mis en avant, conformément à la numismatique de l'antique Byzance. L'allusion d'Eusèbe aux trépieds de Delphes installés à l'hippodrome (construit par Constantin) est confirmée par Zosime : “ il plaça aussi dans une partie de l’hippodrome le trépied de l'Apollon de Delphes, qui comportait même une représentation figurée ( $\alpha \gamma \gamma \alpha \lambda \mu \alpha)$ d'Apollon lui-même »206. Il est difficile de connaître la nature exacte de cette dernière statue. Mais l'archéologie a en tout cas confirmé la présence d'une colonne formée de trois corps de serpents entrelacés et supportant un trépied : il s'agit du monument votif offert par les Grecs au sanctuaire d'Apollon delphien après la victoire de Platées sur les Perses (en 479 av. J.-C.) ${ }^{\mathbf{2 0 7}}$.

Il faut maintenant tenter d'apprécier ce que Constantin pouvait bien penser des deux grands thèmes païens (troyen et apollinien) si richement illustrés par la décoration de sa capitale et en particulier par les statues du Zeuxippe. On s'accorde maintenant à reconnaître que Constantin est d'un point de vue individuel totalement converti au christianisme depuis 312. Il faut en outre ajouter que sa victoire de 324 sur son dernier rival, Licinius, a laissé le champ entièrement libre à l'affirmation d'une légitimité chrétienne esquissée jusqu'alors de manière discrète ${ }^{208}$. Or c'est évidemment à partir de 324 et même plutôt à compter de 330 que furent érigés les monuments de la nouvelle capitale. On ne sera donc pas surpris des positions avancées par l'empereur lui-même dans les années 324-325. Son Discours à l'assemblée des saints, prononcé en grec sans doute le vendredi saint 325 à Nicomédie, évoque la guerre de Troie selon une optique profondément chrétienne. D'après lui, un second Achille sera envoyé à Troie en la personne du Christ ${ }^{209}$, placé à l'origine d'une nouvelle Iliade aboutissant à la fondation d'une Rome chrétienne, en l'occurrence Constantinople. Cette affirmation repose en fait sur l'interprétation de la quatrième Bucolique de Virgile, où l'enfant aimé des dieux qui annonce un nouvel âge d'or est assimilé au Christ. Or il s'agit d'une prédiction de la Sibylle de Cumes, prêtresse d'Apollon.

206 Zos., II, 31, 1, p. 103.

207 Bassett, p. 224-227. Les serpents renvoient évidemment au Python vaincu par Apollon. Ce monument est bien connu par Hdt., IX, 81 ; Paus., X, 13, 9, rapporte qu'à son époque il ne restait déjà plus que la colonne serpentine. Avant d'être retrouvée en 1927 par les fouilles déjà évoquées à propos des bains de Zeuxippe, cette colonne a été décrite seulement par le pèlerin russe Ignace de Smolensk au xıv siècle.

208 V. Puech, Constantin. Le premier empereur chrétien, Paris, 2011, p. 79-110 (chapitre IV : “La légitimité chrétienne »).

${ }^{209}$ Constantin, Discours à l'assemblée des saints, XX, 9, in Constantin, Lettres et discours, trad. P. Maraval, Paris, 2010, p. 146 : “ [Virgile] appelle Achille le Sauveur qui s'élance pour la guerre de Troie et Troie l'univers tout entier. Il a en vérité combattu la puissance mauvaise ennemie, envoyé par sa propre providence et l'ordre de son Père très grand ». 
On peut ainsi également déceler dans ce texte la véritable vision constantinienne du culte d'Apollon. Laissons parler l'empereur :

“ [la Sibylle] était une prêtresse d'Apollon qui portait un diadème, comme le dieu qu'elle honorait ; elle gardait le trépied autour duquel était enroulé le serpent et répondait sous l'effet de l'inspiration à ceux qui l'interrogeaient. C'est par la stupidité de ses parents qu'elle avait été vouée à un tel culte, d'où il ne sortait rien de noble, mais d'indécentes fureurs (...) » ${ }^{210}$.

Constantin avait déjà avancé de telles idées à propos des oracles délivrés par Apollon dans sa lettre aux provinciaux d'Orient, datant de 324, peu après la victoire sur Licinius. Évoquant les empereurs persécuteurs des chrétiens, il affirme :

“ On disait alors qu'Apollon, du fond d'un antre et d'une grotte obscure, et non du haut du ciel, avait déclaré que les justes répandus sur la terre l'empêchaient d'être véridique, et que pour cette raison, les oracles rendus du haut du trépied étaient faux : ce que sa prêtresse, les chevaux dénoués en signe de deuil et poussée par le délire prophétique, déplorait comme étant le mal parmi les hommes » ${ }^{211}$.

Ce passage est une allusion à la consultation de l'oracle d'Apollon Milésien à Didymes par Dioclétien, qui fut ainsi décidé en 303 à mettre en œuvre la grande persécution du christianisme ${ }^{212}$. La vision constantinienne d'Apollon s'avère ainsi contrastée, à l'instar de la manière dont plusieurs auteurs chrétiens ont pu considérer ce “ démon » comme un prophète du monothéisme. A. Busine a bien montré que ce fut en particulier le cas des deux principaux conseillers de Constantin, Lactance et Eusèbe de Césarée : si, d'un côté, ils critiquent la pratique oraculaire, ils tirent par ailleurs des oracles eux-mêmes des prédictions sur la victoire du christianisme ${ }^{213}$. Quoi qu'il en soit de ces interprétations subtiles des oracles, il n'en reste pas moins que le fondateur de Constantinople avait, lui aussi, une vision de ce dieu entièrement marquée par le christianisme. Ce fait est d'autant plus notable que Constantin, avant sa conversion, fut au contraire un adepte des cultes de Sol invictus et d'Apollon ${ }^{214}$ : faut-il invoquer l'attitude du converti qui brûle ce qu'il a adoré ?

210 Constantin, Discours à l'assemblée des saints, XVIII, 2, p. 139-140.

211 Cette lettre est connue par Eusèbe de Césarée, Vie de Constantin, II, 48-60, ici 50, p. 321. L'authenticité des écrits de Constantin contenus dans ce texte est maintenant reconnue, en particulier depuis les travaux de Ch. Pietri.

212 Lactance, De la mort des persécuteurs, XI, 7.

${ }^{213}$ A. Busine, Paroles d'Apollon. Pratiques et traditions oraculaires dans l'Antiquité tardive (II ${ }^{\mathrm{e}}-V I^{\mathrm{e}}$ siècles), Leyde - Boston, 2005, chapitres V et VI. Le comble est atteint quand Apollon est censé annoncer lui-même la fin de son propre culte !

214 Puech, Constantin, p. 61-65. En 310, Constantin a eu une vision d'Apollon en Gaule. 


\section{Le premier empereur chrétien et le patrimoine païen}

Dans le cadre de la fondation de Constantinople, on ne peut donc alléguer une quelconque sympathie personnelle de Constantin pour les cultes liés à l'épopée troyenne et en particulier celui d'Apollon. La manière dont l'empire chrétien a pu vouloir conserver le patrimoine païen a fait l'objet de plusieurs études récentes. Cl. Lepelley ${ }^{215}$ a attiré l'attention sur la législation émise en ce sens et sur son application connue. Une loi de Gratien, Valentinien et Théodose émise à Constantinople en 382 et adressée au duc d'Osrhoène affirme ainsi :

“ L'édifice qui était jadis consacré aux assemblées de la foule, qui sert encore aujourd'hui de lieu de réunion au peuple et où se trouvent, à ce qu'on dit, des statues (simulacra) dont on doit estimer la valeur artistique et non la divinité qu'elles représentent, Nous décrétons qu'il soit toujours ouvert sous l'autorité du conseil de la cité et Nous interdisons de s'opposer à cette décision à l'aide d'un rescrit obtenu par fraude. Pour que l'ensemble de la ville et des assemblées fréquentées puisse en profiter, ton Expérience permettra que le temple soit ouvert à tous pour la célébration des vœux, en vertu de l'autorité de notre décision, pourvu que l'on ne s'imagine pas qu'à l'occasion de cette liberté d'accès il est permis de pratiquer des sacrifices interdits ${ }^{216}$.

Les sacrifices dont il est question ici sont associés à des pratiques divinatoires. L’interdiction générale des sacrifices décidée en 391-392 fut accompagnée d'une prohibition du culte des statues ${ }^{217}$. La législation ultérieure, uniquement connue

215 Cl. LePELley, « Le musée des statues divines. La volonté de sauvegarder le patrimoine artistique païen à l'époque théodosienne ", Cahiers Archéologiques. Fin de l'Antiquité et Moyen Âge 42 (1994), p. 5-15.

216 Code Théodosien, XVI, 10, 8, in Code Théodosien : Les lois religieuses des empereurs romains de Constantin à Théodose II. Volume I: Code Théodosien Livre XVI, éd. Th. Mommsen, trad. J. Rougé, comm. R. Delmaire, Paris, 2005, p. 436-437. Ce texte évoque sans doute précisément le temple d'Édesse, capitale de l'Osrhoène.

217 Code Théodosien, XVI, 10, 10 (loi des trois mêmes empereurs de 391) : " que personne ne révère les statues (simulacra) façonnées de main d'homme " (p. 438-439); Code Théodosien, XVI, 10, 12, 2 (loi des trois mêmes empereurs de 392) : “Si quelqu'un vénérait des images (simulacra) faites de la main de l'homme, qui doivent souffrir des atteintes du temps, en leur offrant de l'encens ou si, exemple ridicule, se mettait tout d'un coup à craindre ce qu'il a lui-même fabriqué, ou couronnait un arbre de bandelettes, ou dressait un autel fait de mottes de terre et tentait d'honorer de vaines images par un présent qui, même de faible valeur, n'en serait pas moins une offense grave pour la religion, cet homme, coupable d'avoir violé la religion, sera frappé de la perte de sa demeure ou de cette propriété dans laquelle il s'est manifestement montré esclave de la superstition des gentils » (p. 444-445). 
pour l'Occident, oscille entre la préservation et la destruction des statues. Et l'on a vu qu'à Constantinople, les temples de l'Acropole furent convertis à des usages profanes par Théodose Ir. Mais il est clair qu'à l'époque constantinienne l'état d'esprit prévalant au sein de l'administration est celui qui est encore décrit par la loi de 382 : les statues doivent être respectées pour leur valeur artistique ${ }^{218}$.

On sait que Constantin a commencé à dépouiller des temples de leurs statues et il est probable que l'ornementation des bains de Zeuxippe reposa au moins en partie sur une telle pratique. Au témoignage de Malalas, on l'a vu, l'empereur laissa subsister les temples d'Hélios-Apollon, Artémis et Aphrodite, mais les priva de revenus. Puisque les statues d'Apollon et Aphrodite sont de loin les mieux représentées dans la collection, on pourrait formuler l'hypothèse que certaines d'entre elles au moins seraient précisément issues de ces temples de l'Acropole de l'ancienne Byzance. Quoi qu'il en soit, à la même époque, le transfert de statues des temples vers des thermes est connu dans d'autres régions du monde romain. Le cas le plus éloquent est celui des grands thermes de l'ouest à Césarée de Maurétanie. Ils contiennent quatre socles de statues où est chaque fois gravée, en lettres de forme tardive, l'expression “ Translata de sordentibus locis » ([statue] « transférée de lieux sordides »). Deux de ces pierres comportent en tête des dédicaces à Hercule et Junon gravées à la fin du II $^{\mathrm{e}}$ siècle. St. Gsell en a tiré la conclusion judicieuse qu'à l'époque chrétienne ces statues avaient été enlevées à des temples ${ }^{219}$. De la même manière, une inscription de Literna en Campanie datable de peu avant 379/383 indique : “ Signa translata ex abditis locis ad celebritatem thermarum Severianarum » (“statues transférées de lieux cachés au regard dans les célèbres thermes Sévériens ») ${ }^{220}$. De façon encore plus explicite qu'à Césarée, ces statues installées dans des thermes provenaient donc de lieux prohibés sous l'empire chrétien. Il faut donc souligner qu'à Constantinople comme ailleurs le déclin des temples païens s'est bien accompagné d'une certaine volonté de sauvegarde des statues, fussent-elles cultuelles.

On doit pour terminer s'interroger sur le rôle exact des statues installées dans les bains de Zeuxippe. L'historiographie a largement considéré cette collection comme un musée d'œuvres d'art. S. Bassett a rappelé que les grands thermes du monde romain, en particulier à Rome et dans les prestigieuses provinces d'Afrique et d'Asie, abritaient de vastes galeries de statues ${ }^{221}$. C'est par exemple le cas des

218 Voir C. Mango, “ Antique Statuary and the Byzantine Beholder », DOP 17 (1963), p. 5375, et H. Saradi-Mendelovici, "Christian Attitudes toward Pagan Monuments in Late Antiquity and Their Legacy in Later Byzantine Centuries ", DOP 44 (1990), p. 47-61.

219 St. Gsell, Cherchel, antique Iol-Caesarea, Alger, 1952, p. 116.

220 Lepelley, “ Le musée », p. 11.

221 Bassett, p. 52. 
thermes de Césarée de Maurétanie déjà évoqués ${ }^{222}$. Dans un contexte païen, les divinités représentées étaient choisies pour leur rapport avec les activités physiques et culturelles propres aux thermes et à leurs dépendances. On trouve ainsi fréquemment Asclépios et Hygie, Dionysos et son cortège, Aphrodite, Héraclès, Apollon et les Muses ${ }^{223}$. Bien sûr, l'iconographie du Zeuxippe a pu répondre pour partie à de telles orientations. Mais on y a observé la cohérence des thèmes troyen et apollinien, liés à la fois au passé byzantin et au présent constantinopolitain. Peut-on ainsi retenir l'idée que Constantin a fait réunir une pure collection muséographique? Une telle interprétation rejoint les réflexions récentes sur le profane dans l'Antiquité tardive. Dans l'introduction d'un stimulant ouvrage sur la question, É. Rebillard et Cl. Sotinel ont ainsi défini le concept de profane comme « un espace de neutralité religieuse sans connotation particulièrement négative ${ }^{224}$. Constantin se serait ainsi borné à séculariser les statues païennes exaltant l'épopée troyenne et le culte d'Apollon. Une telle vision apparaîtrait comme quelque peu réductrice, car elle minorerait la singularité de ces thèmes si évocateurs.

Il s'avère que Constantin attachait une grande importance à la décoration des grands thermes de sa nouvelle capitale. Malalas précise que l'empereur avait prévu l'ouverture des bains de Zeuxippe tous les 11 mai, lors de la fête anniversaire de Constantinople instaurée à partir de la dédicace de la cité en $330^{225}$. C'est dire qu'il considérait la popularité de ce monument comme constitutive de la Rome orientale. Un indice de la conception constantinienne est fourni par la statue de Jules César, dont nous avons vu qu'elle reprend des attributs jupitériens. Il faut rappeler que Constantin, après sa conversion au christianisme, s'est néanmoins fait représenter à Rome sur le modèle d'une statue de culte de Jupiter ${ }^{226}$. À Constantinople, il n'a pas omis de faire ériger un capitole, temple de Jupiter ${ }^{227}$. Pourtant, Constantin ne se sentait plus personnellement concerné par le culte de Jupiter, pas plus que par celui des divinités représentées au Zeuxippe - ses propres écrits suffisent à le montrer. Il faut donc penser que tout ce programme iconographique visait à répondre aux attentes d'une population restée encore

222 Gsell, Cherchel, p. 43-87: on peut ainsi recenser les statues d'Apollon, Jupiter, Esculape, Mercure, Bacchus, Vénus, Hercule.

223 Bassett, p. 52.

224 É. Rebillard et Cl. Sotinel (éd.), Les frontières du profane dans l'Antiquité tardive, Rome, 2010, p. 4.

225 Malalas, Chronique, XIII, 8, p. 247.

226 Puech, Constantin, p. 68-69 et Cl. Parisi Presicce, “Konstantin als Iuppiter. Die Kolossalstatue des Kaisers aus der Basilika an der Via Sacra ", in A. Demandt et J. Engemann (éd.), Konstantin der Grosse, Mayence, 2007, p. 117-131.

227 Puech, Constantin, p. 268. 
majoritairement païenne. Autrement dit, les statues du Zeuxippe furent sélectionnées avec soin pour le sens religieux qu'elles pouvaient conserver. Cette collection relève certes d'une préoccupation patrimoniale, mais cette dernière était orientée par une visée religieuse. Il reste que ces statues ne se trouvaient plus dans des temples. Elles purent alors commencer ce que P. Chuvin a appelé leur " deuxième vie », essentiellement marquée par des pouvoirs magiques, reconnus par une partie au moins de la population ${ }^{228}$. Contrairement à d'autres cas bien attestés ${ }^{229}$, nous ne saurons jamais comment les habitants de Constantinople considérèrent au juste les pouvoirs des statues du Zeuxippe. Mais l'on peut estimer que Constantin, tout en ne croyant plus lui-même à leur valeur religieuse, a accepté de maintenir au moins en partie leur signification ancestrale, jugée encore nécessaire à la population.

\section{Annexe : liste des statues dans l'ordre décrit par Christodoros de Coptos (avec les vers correspondants)}

Déiphobe (1-12)

Eschine (13-16)

Aristote (17-22)

Démosthène (23-31)

Euripide (32-35)

Palaiphatos (36-37)

Hésiode (38-40)

Polyeidos (40-44)

Simonide (44-49)

Anaximène (50-51)

Calchas (52-55)

Pyrrhos (56-60)

Amymone et Poséidon (61-68)

Sappho (69-71)

Apollon (72-77)

Aphrodite (78-81)

Alcibiade (82-85)

\author{
Chrysès (86-91) \\ Jules César (92-96) \\ Platon (97-98) \\ Aphrodite (99-101) \\ Hermaphrodite (102-107) \\ Erinna (108-110) \\ Terpandre (111-116) \\ Périclès (117-120) \\ Pythagore (120-124) \\ Stésichore (125-130) \\ Démocrite (131-135) \\ Héraclès et Augê (136-143) \\ Énée et Créuse (143-154) \\ Hélénos (155-159) \\ Andromaque (160-164) \\ Ménélas et Hélène (165-170) \\ Ulysse (171-175)
}

228 P. Chuvin, Chronique des derniers païens. La disparition du paganisme dans l'Empire romain, du règne de Constantin à celui de Justinien, Paris, 1990, p. 246-252.

229 Par exemple, la statue de Phidaleia, qui était l'épouse du héros fondateur Byzas et défendait elle-même Constantinople, protégeait une porte de la ville : à la fin du v ${ }^{\mathrm{e}}$ ou au début du $\mathrm{vI}^{\mathrm{e}}$ siècle, le fait d'enlever cette statue est réputé avoir entraîné un tremblement de terre (Chuvin, Chronique, p. 251). 
Hécube (175-188)

Cassandre (189-191)

Pyrrhos (Néoptolème) et Polyxène (192-208)

Ajax fils d'Oïlée (209-214)

Oenone et Pâris (215-221)

Darès et Entelle (222-227)

Philon, Philammon ou Milon (228-240)

Charidèmos (241-242)

Mélampus (243-245)

Panthoos, Thymétès, Lampon et Clytios (246-255)

Isocrate (256-258)

Amphiaraos (259-262)

Aglaos (263-265)

Apollon (266-270)

Ajax fils de Télamon (271-276)

Sarpédon (277-282)

Apollon (283-287)

Aphrodite (288-290)
Achille (292-296)

Hermès (297-302)

Apulée (303-305)

Artémis (306-310)

Homère (311-350)

Phérécide (351-353)

Héraclite (354-356)

Cratinos (357-360)

Ménandre (361-366)

Amphitryon (367-371)

Thucydide (372-376)

Hérodote (377-381)

Pindare (382-387)

Xénophon (388-392)

Alcméon (393-397)

Pompée (398-406)

Homère de Byzance (407-413)

Virgile (414-416)

\section{Vincent Puech}

Maître de conférences en histoire ancienne

EA 2449 Dynamiques Patrimoniales et Culturelles (DYPAC)

Institut d'Études Culturelles

et Internationales

Université de Versailles

Saint-Quentin-en-Yvelines

47, boulevard Vauban

78047 Guyancourt Cedex

vincent.puech@uvsq.fr 
